13 China, 210023

\section{Evaluation of sulfate resistance of calcined dolomite activated ground granulated blastfurnace slag}

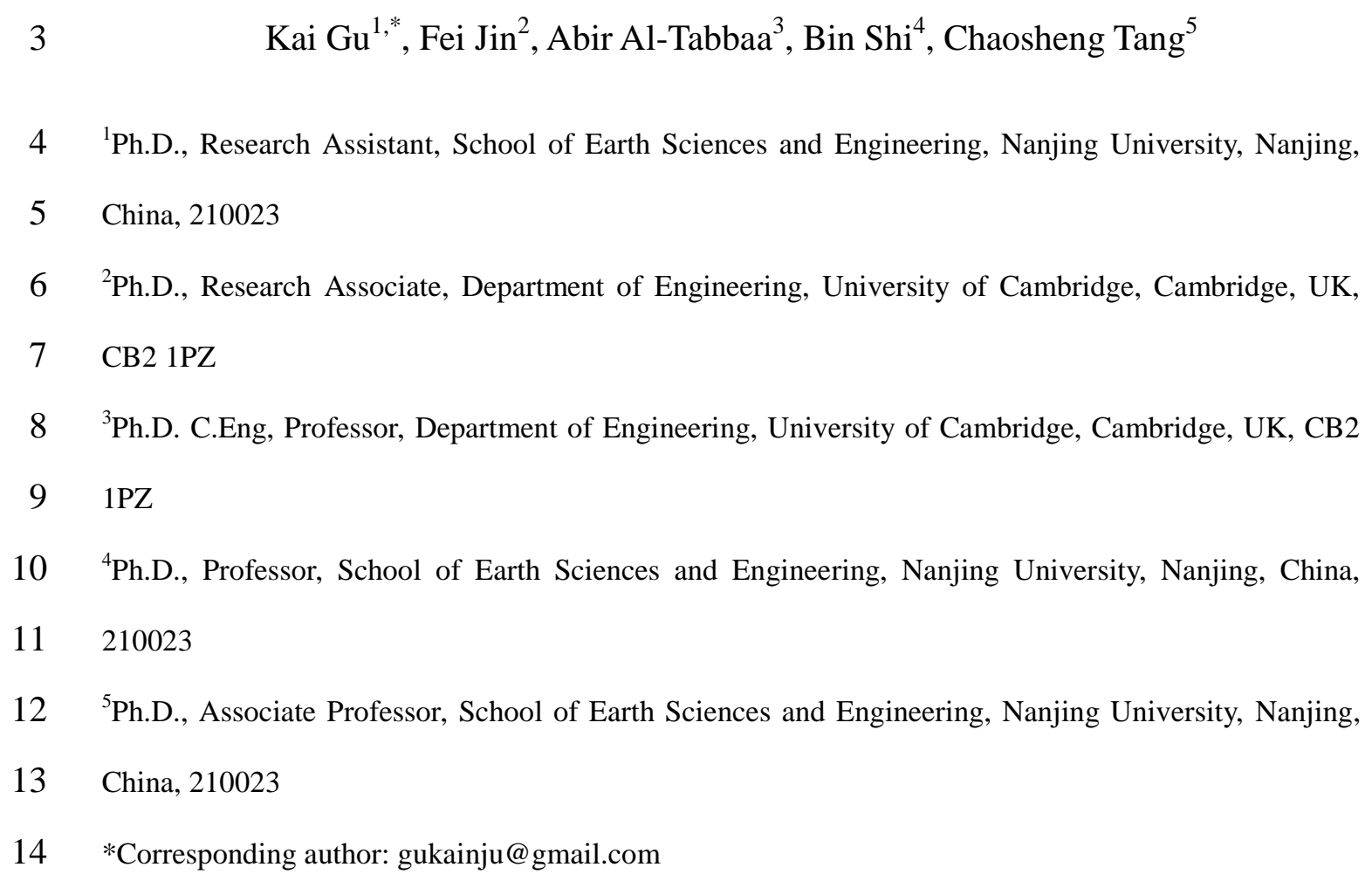

$12{ }^{5}$ Ph.D., Associate Professor, School of Earth Sciences and Engineering, Nanjing University, Nanjing,

$14 \quad *$ Corresponding author: gukainju@gmail.com

ABSTRACT: Aggressive environments significantly influence the durability and serviceability of hardened cement and concrete. This paper presents an evaluation of the resistance of ground granulated blastfurnace slag (GGBS) activated with calcined dolomite, as a novel alkali activator, to 5\% sodium sulfate attack and 5\% magnesium sulfate attack. Two calcined dolomites, D800 and D1000, were prepared in the laboratory at $800{ }^{\circ} \mathrm{C}$ and $1000{ }^{\circ} \mathrm{C}$ respectively. The results demonstrated the good potential of using calcined dolomite activated slag in resisting sulfate attack. Immersion in $\mathrm{Na}_{2} \mathrm{SO}_{4}(\mathrm{aq})$ led to an increase in strength in both the D800 (D800S) and the Portland cement CEM I 52.5N (PCS) activated slag, with a more pronounced effect in the former, while a decrease in the D1000 (D1000S) activated slag. On the 
other hand, calcined dolomite activated slag had less strength loss than PCS after $\mathrm{MgSO}_{4}$ attack. The products of sulfate attack and the deterioration processes are also analyzed by a range of tests including $\mathrm{pH}$, weight change, corroded depth, $\mathrm{XRD}$, TGA and SEM/EDS. After $\mathrm{Na}_{2} \mathrm{SO}_{4}$ attack, the main product on D800S and D1000S was gypsum with a larger amount in the later. Gypsum, thaumasite and M-S-H were the main products of $\mathrm{D} 800 \mathrm{~S}$ and $\mathrm{D} 1000 \mathrm{~S}$ after $\mathrm{MgSO}_{4}$ attack. The better resistance of D800S to sulfate attack was attributed to the absence of portlandite in the hydrated paste. On the other hand, the presence of portlandite in D1000S led to the inhomogeneous sulfate ions inward progression hence the severe deterioration of sample was observed.

Key words: Alkali-activated slag, Calcined dolomite, Sulfate attack, Sodium sulfate, Magnesium sulfate

\section{Introduction}

The resistance of cement-based materials to aggressive environments significantly influences the durability and serviceability of hardened cement and concrete of buildings and infrastructures. External sulfate attack (ESA) is the consequence of impact of the sulfate ions that exist in soils, groundwater, seawater, industrial waste water and mine tailings (Ercikdi et al. 2013; Neville 2004; Tariq and Yanful 2013). It is an important degradation process of cement-based materials. ESA involves the inward progression of sulfate ions through the cement matrix by means of different mechanisms of transportation and the reaction of hydrated cement phases 
with aggressive solutions to form expansive products. This leads to expansion, cracking and deterioration of cement; hence a loss of stiffness, strength and adhesion (Cavdar and Yetgin 2010; Santhanam et al. 2001). Extensive studies have concluded that portlandite and aluminum containing phases are the most vulnerable hydrated cement phases to sulfate attack in the formation of expansive gypsum and ettringite (Hekal et al. 2002; Hill et al. 2003; Torres et al. 2003). The reactions form these two phases are as follows:

$\mathrm{Ca}(\mathrm{OH})_{2}+\mathrm{SO}_{4}{ }^{2-}+\mathrm{H}_{2} \mathrm{O} \rightarrow \mathrm{CaSO}_{4} \cdot 2 \mathrm{H}_{2} \mathrm{O}($ gypsum $)+\mathrm{OH}^{-}$

$\mathrm{CaO} \bullet \mathrm{Al}_{2} \mathrm{O}_{3} \bullet 6 \mathrm{H}_{2} \mathrm{O}+\mathrm{CaSO}_{4} \bullet 2 \mathrm{H}_{2} \mathrm{O}+\mathrm{H}_{2} \mathrm{O} \rightarrow \mathrm{CaO} \bullet \mathrm{Al}_{2} \mathrm{O}_{3} \bullet 3 \mathrm{CaSO}_{4} \bullet 32 \mathrm{H}_{2} \mathrm{O}$ (ettringite)

The enhanced resistance of cement-based materials to ESA can be achieved by reducing the permeability of hardened matrix and/or the amount of portlandite and aluminum containing phases. Thaumasite is another readily formed product by ESA as a result of the reaction between C-S-H and sulfate ions, carbonate ions (either from salts or dissolution of atmospheric $\mathrm{CO}_{2}$ in water) and water (Irassar 2009). Thaumasite sulfate attack (TSA) may occur in mortar or concrete containing limestone, as filler or aggregate, exposed to sulfate environment and cause severe disintegration of mortar and concrete (Irassar 2009).

Most often, ESA has been analyzed in Portland cement, which has been the most widely used cementitious material. However, the cement industry currently contributes approximately 5-8\% of global man-made $\mathrm{CO}_{2}$ emissions (Provis and van Deventer 2014) due to the calcination of limestone and the consumption of fossil fuels. 
of alkali-activated cements (AACs), which utilize a large portion of supplementary cementitious materials (SCMs), such as blastfurnace slag, fly ash and metakaolin with the use of alkali activators (Demirboğa and Gül 2006; Memon et al. 2007; Provis 2013; Shi et al. 2006, 2011; Singhal et al. 2008). The benefits of using AACs are not only in terms of low energy costs and positive environmental impact, but also in terms of enhanced durability (Al-Otaibi 2008; Elahi et al. 2010; Fernandez-Jimenez et al. 2006; Provis and van Deventer 2014; Yüksel et al. 2007), mainly due to the lower content of portlandite in the hydrated cements and their lower permeability to aggressive solutions in moist conditions (Shi et al. 2011). In addition, AACs have been recognized as a more promising option than Portland cement in stabilization/solidification processes, due to lower leachability of contaminants from AACs stabilized hazardous and radioactive wastes (Luna Galiano et al. 2011; Shi and Fernández-Jiménez 2006).

An obstacle in the alkali activation processes is related to the alkali activators. Most conventional activators (caustic hydroxides, silicates) do not exist naturally and are obtained from energy intensive manufacturing processes, which significantly reduces the energy saving credentials associated with AACs (Turner and Collins 2013). Other technical and environmental challenges include their fast setting, high drying shrinkage and their highly corrosive nature of their alkali solutions (Van Deventer et al. 2012; Provis and van Deventer 2014; Yang et al. 2008, 2012). In this context, alternative activators such as reactive magnesia, quicklime, mixture of reactive magnesia and quicklime, calcined dolomite have recently been explored in related 
research initiatives at the University of Cambridge and reported to be effective

91 activators with one or more aforementioned challenges tackled including the reduced

92 drying shrinkage and the enhanced mechanical properties of $\mathrm{MgO}$ cements, the

93 relatively lower energy consumption in the manufacturing processes of these novel

94 activators, etc. (Gu et al. 2014a; b; Jin et al. 2014; Yi et al. 2013; Li 2012), but with

95 limited investigation on durability (Li 2012).

96 The study reported here evaluated the sulfate resistance of calcined dolomite 97 activated GGBS paste in accelerated exposure conditions up to 120 days. Two 98 calcined dolomites were prepared in laboratory conditions and used as alkali 99 activators for slag. Mechanical properties and microstructural changes of samples 100 after attack were analyzed using a range of different tests.

\section{$101 \quad$ Materials and methods}

102

103

\section{Materials}

GGBS from Hanson, UK, and raw dolomite DRB20 from IMERYS, UK, were used in this study. Considering the fact that immediate global replacement of PC by any of the possible alkaline cements is virtually impossible and the dilution of PC with high volumes of SCMs is considered to be one of the possibilities to reduce the impact of PC on environmental issues (Shi et al. 2011). Portland cement CEM I 52.5N from Tarmac, UK, was also used to set a reference for calcined dolomites. The performance of PC activated slag after a short term of sulfate attack will be presented. The chemical compositions and physical properties of these materials are shown in Table 
112 Dolomite DRB20 was used to produce two different calcined dolomites. In the

113 calcination process, $\sim 50 \mathrm{~g}$ of raw dolomite was placed in individual ceramic crucibles

114 and heated under atmospheric conditions to $800{ }^{\circ} \mathrm{C}$ or $1000{ }^{\circ} \mathrm{C}$ in an electric furnace.

115 Those two final temperatures were maintained for $1 \mathrm{~h}$ and then the samples were left to

116 cool down to room temperature. Two calcined dolomites, namely D800 and D1000,

117 were obtained referring to the products calcined at $800{ }^{\circ} \mathrm{C}$ and $1000{ }^{\circ} \mathrm{C}$ respectively.

118 D800 and D1000 were characterized by X-ray diffraction (XRD) and

119 thermogravimetric analysis (TGA). The XRD patterns were collected using a Siemens

120 D5000 X-ray diffractometer with $\mathrm{CuK} \alpha$ radiation. The scanning range was between $5^{\circ}$

121 and $55^{\circ} 2 \theta$. The scanning speed of $1 \mathrm{~s} / \mathrm{step}$ and resolution of $0.05 \%$ step were applied.

122 The TG measurements were carried out using a Perkin Elmer STA 6000 machine by

123 heating the samples from $40{ }^{\circ} \mathrm{C}$ to $1000{ }^{\circ} \mathrm{C}$ at the rate of $10{ }^{\circ} \mathrm{C} / \mathrm{min}$.

124 Preparation of paste and sulfate solutions

125 The D800, D1000 and CEM I were used as activators for the slag, with their

126 dosage controlled at $10 \%$ by weight. The nomenclatures of samples are given in Table

127 2. The slag paste with a water to binder (w/b) ratio of 0.35 was casted in $40 \times 40 \times 40$

$128 \mathrm{~mm}$ cubic molds at $20 \pm 1{ }^{\circ} \mathrm{C}$. The samples were then covered with cling film. After 24

$129 \mathrm{~h}$, the samples were demolded and stored in deionized water at $20 \pm 1^{\circ} \mathrm{C}$ for 28 days.

130 Then the samples were divided into two groups: one group immersed in sulfate

131 solutions for different times and the other group still immersed in deionized water for 
132 reference (Table 2). The 5\% sulfate solutions were prepared by dissolving $50 \mathrm{~g}$

133 sodium sulfate $\left(\mathrm{Na}_{2} \mathrm{SO}_{4}\right)$ or magnesium sulfate $\left(\mathrm{MgSO}_{4}\right)$ in $950 \mathrm{~g}$ deionized water at $13420 \pm 1^{\circ} \mathrm{C}$.

\section{Test Procedure}

136 The compressive strengths of reference samples and the immersed samples were

137 determined at a constant load rate of $2400 \mathrm{~N} / \mathrm{sec}$ in triplicate at each curing age on the

138 CONTROLS Uniframe test machine. For the immersed samples, their weight was

139 measured before both the immersion and the compressive strength test. The solutions

140 were refreshed at each age and the $\mathrm{pH}$ was recorded before renewal using a $\mathrm{pH}$ meter

141 Eutech 520 with an accuracy of 0.01 . The corroded depths of samples were measured

142 using a digital vernier caliper after 90 and 120 days of exposure.

143 The degradation products were characterized by XRD and TGA using the same

144 equipment and parameters as stated in 'Materials' when characterizing the calcined 145 dolomites.

146 The deteriorated microstructure of exposed pastes after 60 days and 90 days was

147 studied by scanning electron microscopy (SEM) combined with energy-dispersive

148 X-ray spectroscopy (EDS). A JEOL 820 machine was used to analyze the

149 microstructure of sample surfaces and a Hitachi S-3400N II machine equipped with a

150 Horiba EX-250 EDS analyzer was used to analyze the deteriorative zone of samples. 


\section{Results and discussions}

152

153

154

155

156

157

158

159

160

161

162

163

164

165

166 167 portlandite in D1000S while no portlandite was detected in D800S.

\section{Characterization of calcined dolomites} $35.8 \%, 54.6 \%$ and $9.6 \%$, respectively, according to the TG curve (Fig.2).

\section{Calcined dolomite activated slag paste}

\section{Development of compressive strength}

Figs.1 and Fig.2 give the XRD and TGA results of D800 and D1000, respectively. Fig. 1 indicates that $\mathrm{D} 800$ consisted of $\mathrm{MgO}, \mathrm{CaO}, \mathrm{CaCO}_{3}$ and a small proportion of undecomposed dolomite. The unknown fraction of undecomposed dolomite makes it difficult to determine the specific proportion of each composition. On the other hand, no dolomite was found in D1000 and hence it was estimated to consist of $\mathrm{MgO}, \mathrm{CaO}$ $\left[\mathrm{Ca}(\mathrm{OH})_{2}\right.$ was also converted into $\left.\mathrm{CaO}\right]$ and $\mathrm{CaCO}_{3}$ with their specific proportion

The hydration properties of calcined dolomite activated slag were investigated by $\mathrm{Gu}$ et al. (2014) in a related paper. The results indicated that relatively higher quantities of $\mathrm{CaO}$ and $\mathrm{MgO}$ in D1000 led to a higher hydration degree of slag with higher contents of C-S-H and hydrotalcite-like phases than D800 did. The pore filling effect of voluminous hydrotalcite-like phases resulted in a more compacted microstructure of D1000S. In addition, $\mathrm{CaO}$ in D1000 caused the formation of

Table 3 presents the compressive strength of the reference and the relative strength of the immersed samples, which are expressed as percentages of the 
171 reference sample at each curing age. The exposure to $\mathrm{Na}_{2} \mathrm{SO}_{4}(\mathrm{aq})$ led to an increase in

172 the compressive strength of D800S and a decrease for D1000S, although there were

173 some fluctuations of the results. After 28 days of exposure, the strength of D800S was

174 slightly increased by $\sim 6.1 \%$ while there was a decrease of $\sim 3.1 \%$ in strength of

175 D1000S. Up to 120 days, there was $~ 12.7 \%$ strength increase of D800S whilst $\sim 10.1 \%$

176 strength decrease of D1000S. The PC activated slag (PCS) also had a slightly

177 enhanced strength after 28 days immersion, but less than D800S. Strength

178 enhancement of alkali-activated slag in $\mathrm{Na}_{2} \mathrm{SO}_{4}(\mathrm{aq})$ was also reported by others

179 (Catinaud et al. 2000; Komljenovic et al. 2013) and was explained by the reduction in

180 the porosity of the pastes, caused by the reaction products between the sample and

181 sulfate solution (Komljenovic et al. 2013; Puertas et al. 2002). Nevertheless, D800S

182 was more resistant to $\mathrm{Na}_{2} \mathrm{SO}_{4}$ attack than PCS, the D1000S showed the lowest

183 resistance to $\mathrm{Na}_{2} \mathrm{SO}_{4}$ attack.

184 Continuous strength decreases of all samples were observed when immersed in

$185 \mathrm{MgSO}_{4}(\mathrm{aq})$. After 28 days of exposure, D800S lost $\sim 7.7 \%$ of strength whilst D1000S

186 lost $\sim 12.5 \%$, and both of them exhibited better performance than PCS, which lost

$187 \sim 16.5 \%$ of strength. The strength of D800S and D1000S after 120 days decreased to

$188 \sim 51.0 \%$ and $\sim 41.3 \%$ of the reference samples, respectively. It appeared that D800S

189 presented a higher resistance to $\mathrm{MgSO}_{4}$ attack than D1000S since the strength loss of

190 D800S was much lower at each age. It can also be concluded that both calcined

191 dolomite activated slags showed higher resistance than PC activated slag to $\mathrm{MgSO}_{4}$

192 attack 
193

194

195

196

197

198

199

201

202

203

pH of sulfate solutions

The $\mathrm{pH}$ of the environment has a significant impact, not only on the chemical reactions but also on the products. Portlandite starts to decompose when the $\mathrm{pH}$ is below 12 (Shi and Stegemann 2000). As the pH drops, C-S-H could continuously release $\mathrm{Ca}^{2+}$ ion until most of the $\mathrm{Ca}^{2+}$ is released when the $\mathrm{pH}$ is below 9 (Komljenović et al. 2012; Shi and Stegemann 2000). In terms of reaction products, Brown (Brown 1981) noticed that ettringite was stable at a $\mathrm{pH}$ of 11.5 , unstable at a $\mathrm{pH}$ of 10 and highly unstable at a pH of 6. Indeed, ettringite starts to decompose when the $\mathrm{pH}$ drops below 10.7 (Beddoe and Dorner 2005).

The initial $\mathrm{pH}$ of $\mathrm{Na}_{2} \mathrm{SO}_{4}(\mathrm{aq})$ and $\mathrm{MgSO}_{4}(\mathrm{aq})$ was 6.4 and 5.7, respectively. After immersion, the $\mathrm{pH}$ of solutions increased rapidly as a result of the release of $\mathrm{OH}^{-}$ions from the samples. After 30 days, the $\mathrm{pH}$ of $\mathrm{Na}_{2} \mathrm{SO}_{4}(\mathrm{aq})$ containing $\mathrm{D} 800 \mathrm{~S}$ was maintained above 12.1 while that containing D1000S was above 12.6 (Fig.3). As for the $\mathrm{MgSO}_{4}(\mathrm{aq}), \mathrm{D} 800 \mathrm{~S}$ induced $\mathrm{pH}$ values staying around 9.0 at each age; whilst D1000S induced a decrease from 9.9 to 9.0 then was stable around 9.0 after 90 days. It should be noted that, since the solutions were refreshed monthly, samples may sometime experience lower $\mathrm{pH}$ environment than the result given in Fig. 3 considering the initial $\mathrm{pH}$ of solutions. As a result, the decomposition of portlandite, $\mathrm{C}-\mathrm{S}-\mathrm{H}$ and/or ettringite should have occurred when the $\mathrm{pH}$ was below the lines marked in Fig.3.

According to the results, D1000S induced higher $\mathrm{pH}$ in both two sulfate solutions and this could be attributed to its higher content of portlandite, which is 
214 easier to release $\mathrm{OH}^{-}$than C-S-H (Taylor and Gollop 1997). In addition, lower pH of

$215 \mathrm{MgSO}_{4}(\mathrm{aq})$ than $\mathrm{Na}_{2} \mathrm{SO}_{4}(\mathrm{aq})$ can be explained by the formation of insoluble $\mathrm{Mg}(\mathrm{OH})_{2}$,

216 which significantly reduced the concentration of $\mathrm{OH}^{-}$in the solutions.

\section{Weight changes}

218 Changes of weight after exposure were used as an indicator for the resistance of

219 samples to sulfate attack in most relevant studies (Al-Amoudi 2002; Makhloufi et al.

220 2012). Fig.4 summarizes the weight changes of the samples after different exposure

221 times and reveals that there were weight increases with time for all sample. In the

$222 \mathrm{Na}_{2} \mathrm{SO}_{4}(\mathrm{aq})$, weight changes gradually increased with time and achieved an increase

223 of $0.22 \%$ for D800S and $0.66 \%$ for D1000S after 120 days of exposure. The relatively

224 larger weight increase of D1000S can be attributed to the higher content of portlandite

225 in D1000S, which led to the more intensive reaction between the sample and the

226 solution. Up to 28 days, PCS showed a larger weight increase than D800S while

227 slightly smaller than D1000S.

228 Notably higher weight increases of samples immersed in $\mathrm{MgSO}_{4}(\mathrm{aq})$ were

229 observed. D800S showed $+2.59 \%$ weight gain after 28 days and rapidly increased to

$230+10.68 \%$ after 120 days. By contrast, D1000S showed much smaller weight gain, i.e.

$231+0.95 \%$ after 28 days and $+4.85 \%$ after 120 days. Regarding to PCS, it had a $+2.26 \%$

232 weight gain after 28 days exposure, slightly smaller than D800S.

233 As can be seen, D800S showed smaller weight changes than D1000S in

$234 \mathrm{Na}_{2} \mathrm{SO}_{4}$ (aq) while larger in $\mathrm{MgSO}_{4}$ (aq) (Fig.4). The explanation should involve the 
235 different formats of inward deterioration progression in D800S and D1000S 236 (discussed in Section 3.7).

237 Corroded depth

238 Fig.5 gives the measured corroded depths of samples after 90 and 120 days of 239 exposure. It is apparent that the corroded depth increased with exposure time. The 240 relatively moderate reaction between the samples and $\mathrm{Na}_{2} \mathrm{SO}_{4}(\mathrm{aq})$ led to small 241 corroded depths and no obvious visual degradation of the samples was observed. Up 242 to 120 days, the depth was $\sim 0.20 \mathrm{~mm}$ for D800S and $\sim 0.38 \mathrm{~mm}$ for D1000S.

243 Much larger corroded depths were observed on samples immersed in $\mathrm{MgSO}_{4}(\mathrm{aq})$.

244 D800S, which had smaller strength loss (Table 3), however, had thicker deteriorative 245 surface than D1000S. The different formats of inward deterioration progress on 246 samples are likely to be attributable to this behaviour. The images took after 90 and 247120 days of exposure (Fig.6) indicated that the $\mathrm{MgSO}_{4}(\mathrm{aq})$ gradually penetrated into 248 D800S and only caused significant spalling along the edges rather than on the surface 249 (Fig.6a and c). In this case, the thickness of deteriorative surface was homogeneous. 250 By contrast, the attack products on D1000S caused significant expansion in some 251 areas due to the high content of portlandite. Therefore, not only spalling along the 252 sample edges, but also bulging on the surface was observed. The deterioration was 253 accelerated within the bulging hence the corroded depth was not homogeneous and 254 may be much thicker than those 'normal' areas. However, only 'normal' areas were 255 measured when performed the corroded depth measurement. As a consequence, the 
measured corroded depths of D1000S were smaller than those of D800S.

\section{$X R D$ and TG analysis}

After exposure, the XRD and TGA of the paste from the deteriorative surface of samples showed different reaction products in D800S and D1000S (Fig.7-10). Fig.7 indicates that, after 60 days of exposure in $\mathrm{Na}_{2} \mathrm{SO}_{4}(\mathrm{aq})$, the major products were gypsum accompanied by minor amount of ettringite in D800S deteriorative surface.

The small quantity of ettringite was attributable to the high sulfate concentration of the solutions ( 33800 ppm in $\mathrm{Na}_{2} \mathrm{SO}_{4}(\mathrm{aq})$ and $~ 40000 \mathrm{ppm}$ in $\left.\mathrm{MgSO}_{4}(\mathrm{aq})\right)$ since gypsum was the primary reaction product of sulfate attack when the sulfate ion concentration was higher than 8000 ppm (Santhanam et al. 2001). C-S-H and calcite were still observed due to the moderate reaction between $\mathrm{Na}_{2} \mathrm{SO}_{4}(\mathrm{aq})$ and the samples. As for D1000S, all phases which observed in D800S were also observed but with different intensities. Clearly, there was still a considerable amount of porlandite left, because fresh paste may be intermixed with the corroded part during the preparation of samples for analysis when the samples' corrode depth in $\mathrm{Na}_{2} \mathrm{SO}_{4}(\mathrm{aq})$ was shallow (Fig.5). TGA results which were given in Fig.8 consisted well with the XRD observation. The weight losses of ettringite, gypsum and C-S-H overlap in the temperature range of $80{ }^{\circ} \mathrm{C}$ to $170{ }^{\circ} \mathrm{C}$ (Cassagnabère et al. 2009; Ciobanu et al. 2012) and hence it is difficult to quantitatively estimate the individual amounts of each phase in the deteriorative zone. Ettringite was also observed to decompose at a lower temperature $\left(50{ }^{\circ} \mathrm{C}\right.$ to $80{ }^{\circ} \mathrm{C}$ ) (Ciobanu et al. 2012; Gruskovnjak et al. 2008) therefore 
a very small shoulder in this range was shown. In comparison to D800S, the presence of portlandite in D1000S, which decomposes at $430-460{ }^{\circ} \mathrm{C}$, was confirmed in the DTG curve.

After 60 days of exposure in $\mathrm{MgSO}_{4}(\mathrm{aq})$, the presence of brucite was confirmed in attacked calcined dolomite activated slag pastes (Fig.9). Its low intensity could be attributed to the old age of the analyzed sample, in which case the dissolution of brucite layer occurred and other reaction products had already formed. Nevertheless, brucite was more ready to form in D1000S because it notably consumes portlandite, which was only found in D1000S. The pronounced aggression of $\mathrm{MgSO}_{4}(\mathrm{aq})$ considerably increased the amount of the reaction products, mainly gypsum, whose peaks of high intensity were observed in both samples. On the other hand, ettringite was more ready to decompose because of the low $\mathrm{pH}$ environment (Fig.3) and high $\mathrm{SO}_{4}{ }^{2-}$ concentration, so only weak peaks were detected. In this context, the strong characteristic peaks at $2 \theta=26.1^{\circ}$ and $32.2^{\circ}$ can be mainly attributed to the formation of thaumasite, which is difficult to distinguish from ettringite (Irassar 2009; Torres et al. 2003). Extensive literature reported the formation of thaumasite in the presence of limestone under sulfate attack (Bellmann and Stark 2007; Irassar et al. 2003, 2005; Kakali et al. 2003; Lee et al. 2008; Tsivilis et al. 2007). Although cold environments $\left(<15^{\circ} \mathrm{C}\right)$ are preferable to thaumasite formation (Bellmann and Stark 2007; Köhler et al. 2006; Tsivilis et al. 2007), it was also observed at ambient temperature (Irassar et al. 2003, 2005; Lee et al. 2008). As a result of magnesium attack, C-S-H gradually converted into non-cementitious M-S-H (Gollop and Taylor 1996; Santhanam et al. 
299 2003) and/or simply silica gel $\left(\mathrm{SiO}_{2} \cdot \mathrm{xH}_{2} \mathrm{O}\right)$ (Collepardi 2003) until most of $\mathrm{Ca}^{2+}$ was

300 released when $\mathrm{pH}$ dropped below 9. Therefore, $\mathrm{C}-\mathrm{S}-\mathrm{H}$ was not detected in 301 deteriorative D800S and D1000S (Fig.9). The characteristic peaks of 302 non-cementitious M-S-H are recognized as board humps but difficult to detect by 303 XRD (Jin and Al-Tabbaa 2013). Surprisingly, small amount of portlandite, which was 304 supposed to have been depleted, was still detected in D1000S. It seems that this part 305 of portlandite was inaccessible to the solution, owing to the harbouring effect of other 306 phases. Calcium sulfate hydrate, other than gypsum, was also detected in the attack 307 products.

308 According to the TGA results of samples immersed in $\mathrm{MgSO}_{4}$ (aq) (Fig.10), the 309 broad trough of C-S-H was replaced by a much narrower but deeper trough at $310130{ }^{\circ} \mathrm{C}$, which represented the decomposition of gypsum. The decomposition of 311 thaumasite mainly happened between 140-200 ${ }^{\circ} \mathrm{C}$ (Kresten and Berggren 1976) and 312 slightly overlapped with gypsum. M-S-H, which decomposes at $\sim 400{ }^{\circ} \mathrm{C}$ and overlaps 313 with hydrotalcite-like phases, was confirmed although it was not clearly detected by

314 XRD analysis. The minor amount of portlandite left in D1000S induced the weight 315 loss at $\sim 440{ }^{\circ} \mathrm{C}$. In comparison to the samples in $\mathrm{Na}_{2} \mathrm{SO}_{4}$ (aq) (Fig.8), the amounts of 316 calcite in D800S and D1000S were significantly smaller, due to the participation of 317 calcite in forming thaumasite.

Microstructural analysis

319 Fig.11 shows the SEM images of D800S surface after exposure to $\mathrm{Na}_{2} \mathrm{SO}_{4}(\mathrm{aq})$. 
320 The microstructure appears to be looser than the fresh D800S paste, whose SEM 321 image is not shown here. The inconspicuously corroded surface was covered with 322 gypsum, with some large crystals and small cracks observed.

323 Fig.12 presented the degraded surfaces of the samples after exposed to $324 \mathrm{MgSO}_{4}(\mathrm{aq})$ for 60 days. In D800S (Fig.12a and b), the brucite layer had almost been 325 destroyed by that time, hence the severe decalcification of C-S-H was clearly 326 observed, leaving porous M-S-H. Gypsum crystals were found randomly distributed 327 on the surface while ettringite and thaumasite were difficult to identify. As for 328 D1000S (Fig.12c and d), the brucite layer was observed to have decomposed. The 329 gypsum layer, which was originally beneath the brucite layer (Santhanam et al. 2003), 330 was found to cover the surface due to the large amount of available $\mathrm{Ca}^{2+}$ released 331 from D1000S. Small quantity of ettringite was also found. In this case, decalcified 332 C-S-H cannot be observed in the images taken on the sample surface.

333 Fig.13 shows the deteriorative zone profiles of samples after 90 days attack. As 334 can be seen, both D800S and D1000S had a narrow deteriorative zone $(<300 \mu \mathrm{m})$ 335 after 90 days immersion in $\mathrm{Na}_{2} \mathrm{SO}_{4}(\mathrm{aq})$, indicating a moderate reaction between the 336 samples and the solution and agreed well with the corroded depth result (Fig.5). In 337 addition, the relatively denser structure of D800S deteriorative zone than the fresh 338 paste (Fig.13a) implied the pore filling effect of reaction products, by which the 339 compressive strength of sample was enhanced (Table 3). The micro cracks were only 340 observed beneath the deteriorative zone, suggesting a potential weak structure after 341 the attack. Regarding to D1000S, although no clear difference in porosity from the 
342 outer area to the inner area was observed, the absence of slag particles in the 343 deteriorative zone indicated the precipitation the reaction products on the surface, 344 sometimes in a pore (Fig.13b). The consumption of $\mathrm{Ca}^{2+}$ by the $\mathrm{Na}_{2} \mathrm{SO}_{4}(\mathrm{aq})$ in 345 forming these products caused the strength loss over time.

346 D800S had a thicker deteriorative zone than D1000S when immersed in $347 \mathrm{MgSO}_{4}(\mathrm{aq})$ (Fig.13c and d). It can be attributed to (1) the loose structure of D800S, 348 which made the inward progression of the aggressive solution easier thus more attack 349 products (Fig.4); and (2) the formation of thaumasite. Due to the larger amount of 350 available $\mathrm{CO}_{3}{ }^{2-}$ in D800S, more thaumasite formed after attack (Fig.9) led to a higher 351 degradation degree. As suggested by the literature (Santhanam et al. 2002), the 352 deteriorative zone can be divided into two parts: Zone I (the disintegrated surface 353 zone) and Zone II (the zone of deposition of attack products), as marked in Fig.13c 354 and $\mathrm{d}$. The degradation of paste and the precipitation of reaction products induced 355 inhomogenous and anfractuous layers in Zone II of D800S, with micro cracks and 356 voids developed (although there were original voids before attack). Deposit layers of 357 products were relatively more homogenous in Zone II of D1000S, suggesting a 358 gradual penetration process of aggressive solution due to its lower porosity. However, 359 such relatively stratified structure of D1000S deteriorative zone was ready to destroy 360 when external pressure was applied and therefore D1000S had higher strength loss 361 after attack.

362 Fig.14 presented the deteriorative zones of samples with EDS analysis results.

363 Fig.14a, which shows the surface of D800S immersed in $\mathrm{Na}_{2} \mathrm{SO}_{4}(\mathrm{aq})$, illustrates the 
364 dense matrix filled with a small amount of attack products. The penetration of 365 aggressive solution could be retarded since no micro cracks were observed. A thin 366 layer of calcite was observed on the surface of D1000S immersed in $\mathrm{Na}_{2} \mathrm{SO}_{4}(\mathrm{aq})$ 367 (Fig.14b). Its formation can be attributed to the carbonation of D1000 during curing.

368 Fig.14c is the magnification of the red square marked in Fig.13c from D800S 369 immersed in $\mathrm{MgSO}_{4}(\mathrm{aq})$. A clear gypsum layer was observed with micro cracks 370 developed. Meanwhile, between the deteriorative zone and the fresh paste, a wide 371 crack formed and thereafter the new attack products would deposit in the crack. The 372 area with a smooth surface had a low $\mathrm{Ca} / \mathrm{Si}$ atomic ratio $(\sim 1.3)$ due to the 373 decalcification of C-S-H, resulting in the coexistence of silica gel or M-S-H with $374 \mathrm{C}-\mathrm{S}-\mathrm{H}$ gel. The decreased $\mathrm{Ca} / \mathrm{Si}$ atomic ratio explained the decrease in strength 375 (Komljenović et al. 2012), which led to a more smooth surface than the fresh paste. 376 Indeed, the formation of brucite and gypsum caused the decalcification of C-S-H and 377 hence the convert of C-S-H to non-cementious M-S-H was confirmed in Fig.14d, with 378 small amount of residual $\mathrm{Ca}^{2+}$ detected. Cracks and voids were ready to form due to 379 the poor performance of $\mathrm{M}-\mathrm{S}-\mathrm{H}$ in binding. D1000S immersed in $\mathrm{MgSO}_{4}(\mathrm{aq})$ also 380 showed the deposit of attack products (mainly gypsum) within the slag matrix 381 (Fig.14e). The darker grey conjunction area of the gypsum layer and slag matrix was 382 probably due to the lower $\mathrm{Ca}$ content after decalcification. The unreacted slag 383 particles incorporated matrix appeared to retard the development of micro cracks to 384 some extent. 
$\mathrm{Na}_{2} \mathrm{SO}_{4}$ attack

No clear visual sign of deterioration on samples immersed in $\mathrm{Na}_{2} \mathrm{SO}_{4}(\mathrm{aq})$ suggested a high resistance of calcined dolomite activated slag to attack. For D800S, $\mathrm{OH}^{-}$ions released from cementitious $\mathrm{C}-\mathrm{S}-\mathrm{H}$, which only occurs if portlandite is

390 locally absent (Chen et al. 2006), rapidly increased the $\mathrm{pH}$ of the solution after 391 immersion. On the other hand, the $\mathrm{Ca}^{2+}$ ions released from $\mathrm{C}-\mathrm{S}-\mathrm{H}$ reacted with the 392 solution to form gypsum according to:

$$
\mathrm{Ca}^{2+}+\mathrm{SO}_{4}{ }^{2-}+\mathrm{H}_{2} \mathrm{O} \rightarrow \mathrm{CaSO}_{4} \cdot 2 \mathrm{H}_{2} \mathrm{O}(\text { gypsum })
$$

394 This process may cause the loss of strength since C-S-H provides the binding capacity, 395 but the pore filling effect of gypsum may reduce the porosity of sample and somewhat 396 compact the structure, resulting in an increase rather than a decrease in strength. 397 Moreover, the compacted structure also retarded the inward movement of the 398 aggressive solution. As for D1000S, that $\mathrm{OH}^{-}$ions readily released from portlandite to 399 some extent prevents the dissolution of C-S-H, but also created high porosity with 400 increased permeability of the deteriorative zone. The precipitation of expansive attack 401 products in the pores (as observed in Fig.13b) may destroy the local structure and 402 became a stress raiser during strength test. Consequently, a decreased strength was 403 obtained although D1000S had a denser matrix than D800S. The very thin layer of 404 calcite formed on the D1000S sample surface was due to the carbonation during 405 curing. Since calcite can result in a reduction of the material porosity and favor the 
407 calcite could to some extent increase the sulfate resistance of D1000S.

$408 \quad 3.7 .2 \mathrm{MgSO}_{4}$ attack

409 After immersion in $\mathrm{MgSO}_{4}(\mathrm{aq})$, a layer of brucite rapidly formed on the surface

410 with a gypsum layer beneath (Bonen and Cohen 1992; Santhanam et al. 2002),

411 according to the reaction:

$$
\mathrm{Ca}^{2+}+\mathrm{OH}^{-}+\mathrm{Mg}^{2+}+\mathrm{SO}_{4}{ }^{2-}+\mathrm{H}_{2} \mathrm{O} \rightarrow \mathrm{CaSO}_{4} \cdot 2 \mathrm{H}_{2} \mathrm{O}(\text { gypsum })+\mathrm{Mg}(\mathrm{OH})_{2}
$$

413 (brucite)

414 On the one hand, the formation of brucite consumed a considerable amount of $\mathrm{OH}^{-}$ 415 and accelerated the decalcification of C-S-H (Bonen 1993). On the other hand, the 416 precipitation of brucite in turn results in a low and non-uniform rate of diffusion of $417 \mathrm{SO}_{4}{ }^{2-}$ parallel to the surface (Bonen and Cohen 1992). Due to the absence of 418 portlandite in $\mathrm{D} 800 \mathrm{~S}$, C-S-H was directly attacked by $\mathrm{MgSO}_{4}(\mathrm{aq})$ therefore the 419 formations of M-S-H and gypsum were clearly observed after 60 days of exposure 420 (Fig.12b). Consequently, the deteriorative zone with porous structure became more 421 accessible to sulfate ions and provided a favorable scenario for thaumasite formation 422 in the presence of C-S-H, sulfate ions, carbonate ions (mainly provided by D800), and 423 water, according to the following reaction:

$$
\mathrm{C}-\mathrm{S}-\mathrm{H}+\mathrm{SO}_{4}{ }^{2-}+\mathrm{CO}_{3}{ }^{2-}+\mathrm{H}_{2} \mathrm{O} \rightarrow \mathrm{CaSiO}_{3} \bullet \mathrm{CaCO}_{3} \bullet \mathrm{CaSO}_{4} \bullet 15 \mathrm{H}_{2} \mathrm{O} \text { (thaumasite) }
$$

425 As a result, a large amount of thaumasite (Fig.9) led to a thick deteriorative zone with 426 inhomogenous and anfractuous layers of precipitated attack products, which is 427 manifested by strength losses over time. 

on D1000S, which led to a high porosity of the surface. Expansive products filled the

430 pores and caused expansive damages in some areas, where the penetration of the 431 aggressive solution was accelerated. In this case, the reaction within these areas was 432 also accelerated and the expansion caused the formation of bulging on the surface. 433 The bulging may cause stress concentration, which explained the larger strength loss 434 of D1000S after attack than D800S, although D1000S had denser matrix, lower 435 permeability, and less vulnerable $\mathrm{C}-\mathrm{S}-\mathrm{H}$ to attack and hence thinner deteriorative zone 436 (Fig.13d).

Hydrotalcite-like phases were not significantly affected by sulfate attack, with 438 only a slight change in $\mathrm{Mg} / \mathrm{Al}$ atomic ratio observed according to the literature 439 (Gollop and Taylor 1996; Komljenovic et al. 2013). The dominant reactions in 440 forming brucite, $\mathrm{M}-\mathrm{S}-\mathrm{H}$, gypsum and thaumasite in $\mathrm{MgSO}_{4}(\mathrm{aq})$ caused the 441 inconspicuous presence of hydrotalcite-like phases hence it was difficult to determine 442 the changes on hydrotalcite-like phases.

\section{Conclusions}

444 The results in this study demonstrated that D800 activated slag (D800S) was more 445 resistant to $\mathrm{Na}_{2} \mathrm{SO}_{4}$ attack than PC activated slag (PCS) while D1000 activated slag 446 (D1000S) showed the lowest resistance. In addition, calcined dolomites activated slag 447 was more resistant to $\mathrm{MgSO}_{4}$ attack than PCS. The absence of portlandite in D800S 448 induced C-S-H susceptible to solution and calcite in D800 induced the formation of 
449 thaumasite, but D800S had less strength loss than D1000S in terms of $\mathrm{MgSO}_{4}$ attack, 450 which can be illustrated by the inhomogeneous sulfate ions inwards progression on 451 D1000S. After $\mathrm{Na}_{2} \mathrm{SO}_{4}$ attack, the main product on D800S and D1000S was gypsum 452 with a larger content found in the later. Gypsum, thaumasite and M-S-H were the 453 main products of D800S and D1000S after $\mathrm{MgSO}_{4}$ attack. Calcination temperature of 454 dolomite is the controlling factor on the sulfate resistance of calcined dolomite 455 activated slag, by changing the hydration products and the porosity of hydrated paste. 456 By properly changing the calcination temperature, the amount of generated 457 portlandite and the porosity of hydrated paste can be reduced; therefore the resistance 458 to sulfate attack can be enhanced.

\section{Acknowledgements}

460 This study was supported by the China Scholarship Council, the Key Project of the

461 Natural Science Foundation of China (41230636) and the National Basic Research 462 Program of China (2011CB710605). The second author also wants to thank the 463 Cambridge Trust and the China Scholarship Council for the financial support.

\section{References}

465 Al-Amoudi, O. (2002). “Attack on plain and blended cements exposed to aggressive sulfate

466 environments." Cem. Concr Comp., 24, 305-316. 
Beddoe, R. E., and Dorner, H. W. (2005). "Modelling acid attack on concrete: Part I. The essential mechanisms." Cem. Concr.Res., 35(12), 2333-2339.

Bellmann, F., and Stark, J. (2007). "Prevention of thaumasite formation in concrete exposed to sulphate attack." Cem. Concr.Res., 37(8), 1215-1222. silica fume-bearing Portland cement mortars." Cem. Concr.Res., 23, 541-553. and mineralogical analyses." Cem. Concr.Res., 22(1), 169-180.

Brown, P. (1981). "An evaluation of the sulfate resistance of cements in a controlled environment." Cem. Concr.Res., 11, 719-727.

Cassagnabère, F., Mouret, M., and Escadeillas, G. (2009). "Early hydration of clinker-slag-metakaolin combination in steam curing conditions, relation with mechanical properties." Cem. Concr.Res., 39(12), 1164-1173. leaching mechanisms in cement-based materials.” Cem. Concr.Res., 25, 913-919.

484 Cavdar, A., and Yetgin, S. (2010). "Investigation of mechanical and mineralogical properties of mortars subjected to sulfate." Constr. Build. Mater., 24(11), 2231-2242. 
Chen, J. J., Thomas, J. J., and Jennings, H. M. (2006). “Decalcification shrinkage of cement paste." Cem. Concr.Res., 36(5), 801-809.

Ciobanu, C., Lazău, I., and Păcurariu, C. (2012). "Investigation of the cellulose ethers effect on the Portland cement hydration by thermal analysis.” J. Therm. Anal. Calorim., 112(1), 325-330.

Collepardi, M. (2003). "A state-of-the-art review on delayed ettringite attack on concrete." Cem. Concr Comp., 25(4-5), 401-407.

Demirboğa, R., and Gül, R. (2006). “Production of high strength concrete by use of industrial by-products.” Build. Environ., 41(8), 1124-1127.

Van Deventer, J. S. J., Provis, J. L., and Duxson, P. (2012). “Technical and commercial progress in the adoption of geopolymer cement." Miner. Eng., 29, 89-104.

Elahi, A., Basheer, P. A. M., Nanukuttan, S. V., and Khan, Q. U. Z. (2010). "Mechanical and durability properties of high performance concretes containing supplementary cementitious materials." Constr. Build. Mater., 24(3), 292-299.

Ercikdi, B., Baki, H., and İzki, M. (2013). "Effect of desliming of sulphide-rich mill tailings on the long-term strength of cemented paste backfill." J. Environ. Manage., 115, 5-13.

Fernandez-Jimenez, A., García-Lodeiro, I., and Palomo, A. (2006). "Durability of alkali-activated fly ash cementitious materials." J. Mater. Sci., 42(9), 3055-3065. 
Glasser, F., Marchand, J., and Samson, E. (2008). "Durability of concrete—degradation phenomena involving detrimental chemical reactions." Cem. Concr.Res., 38, 226-246.

Gollop, R., and Taylor, H. (1996). "Microstructural and microanalytical studies of sulfate attack. IV. Reactions of a slag cement paste with sodium and magnesium sulfate solutions." Cem. Concr.Res., 26(7), 1013-1028.

Gruskovnjak, A., Lothenbach, B., Winnefeld, F., Figi, R., Ko, S.-C., Adler, M., and Mäder, U. (2008). “Hydration mechanisms of super sulphated slag cement." Cem. Concr.Res., 38(7), 983-992.

Gu, K., Jin, F., Al-Tabbaa, A., and Shi, B. (2014a). “Activation of ground granulated blast furnace slag by using calcined dolomite.” Constr. Build. Mater., 68, 252-258.

Gu, K., Jin, F., Al-Tabbaa, A., Shi, B., and Liu, J. (2014b). "Mechanical and hydration properties of ground granulated blast furnace slag pastes activated with $\mathrm{MgO}-\mathrm{CaO}$ mixtures." Constr. Build. Mater., 69, 101-108.

Hekal, E. E., Kishar, E., and Mostafa, H. (2002). "Magnesium sulfate attack on hardened blended cement pastes under different circumstances." Cem. Concr.Res., 32(9), 1421-1427.

Hill, J., Byars, E. A., Sharp, J. H., Lynsdale, C. J., Cripps, J. C., and Zhou, Q. (2003). “An experimental study of combined acid and sulfate attack of concrete." Cem. Concr Comp., 25(8), 997-1003. 
Irassar, E., Bonavetti, V., and Gonzalez, M. (2003). "Microstructural study of sulfate attack on ordinary and limestone Portland cements at ambient temperature." Cem. Concr.Res., 33, 31-41.

Irassar, E. F. (2009). "Sulfate attack on cementitious materials containing limestone filler — A review." Cem. Concr.Res., 39(3), 241-254.

524 Concr.Res., 36(4), 697-706.

Irassar, E. F., Bonavetti, V. L., Trezza, M. A., and González, M. A. (2005). "Thaumasite formation in limestone filler cements exposed to sodium sulphate solution at $20^{\circ} \mathrm{C}$." Cem. Concr Comp., 27(1), 77-84.

Jin, F., and Al-Tabbaa, A. (2013). "Thermogravimetric study on the hydration of reactive magnesia and silica mixture at room temperature.” Thermochim. Acta, 566, 162-168.

Jin, F., Gu, K., Abdollahzadeh, A., and Al-Tabbaa, A. (2014). "Effect of different reactive MgOs on the hydration of MgO-activated ground granulated blastfurnace slag paste.” J.Mater. Civ. Eng., doi:10.1061/(ASCE)MT.1943-5533.0001009.

Kakali, G., Tsivilis, S., Skaropoulou, A., Sharp, J. H., and Swamy, R. N. (2003). "Parameters affecting thaumasite formation in limestone cement mortar." Cem. Concr Comp., 25(8), 977-981.

Komljenovic, M., Bascarevic, Z., Marjanovic, N., and Nikolic, V. (2013). "External sulfate attack on alkali-activated slag." Constr. Build. Mater., 49, 31-39. 
538 Komljenović, M. M., Baščarević, Z., Marjanović, N., and Nikolić, V. (2012). “Decalcification resistance of alkali-activated slag.” J. Hazard. Mater., 233-234, 112-121.

540 Kresten, P., and Berggren, G. (1976). "The thermal decomposition of thaumasite from Mothae Kimberlite Pipe, Lesotho, Southern Africa.” J. Therm. Anal., 9, 23-28. on the deterioration of mortars and pastes exposed to sulfate solutions at ambient temperature."

Li, X. (2012). "Mechanical properties and durability performance of reactive magnesium cement concrete, PhD thesis." University of Cambridge, UK. municipal solid waste incineration residue using fly ash-based geopolymers.” J. Hazard. Mater., with quaternary binders to sulfuric acid solution.” Constr. Build. Mater., 26(1), 497-504. mortar for ferrocement." Build. Environ., 42(7), 2710-2717.

554 Neville, A. (2004). "The confused world of sulfate attack on concrete." Cem. Concr.Res., 34(8), 1275- 
556 Provis, J. L. (2013). “Geopolymers and other alkali activated materials: why, how, and what?” Mater. and Struct., 47(1-2), 11-25.

Provis, J. L., and van Deventer, J. S. J. (2014). Alkali Activated Materials:State-of-the-Art Report, RILEM TC 224-AAM. RILEM State-of-the-Art Reports, Springer, Netherlands, Dordrecht. Construccion, 52(c), 55-71. Concr.Res., 31, 845-851. Summary of experimental results." Cem. Concr.Res., 32, 915-921. Proposed mechanisms." Cem. Concr.Res., 33, 341-346. wastes with alkali-activated cements." J. Hazard. Mater., 137(3), 1656-1663. 
Shi, C., Jiménez, A. F., and Palomo, A. (2011). "New cements for the 21st century: The pursuit of an alternative to Portland cement." Cem. Concr.Res., 41(7), 750-763.

Shi, C., Krivenko, P., and Roy, D. (2006). Alkali-activated cements and concretes. Taylor \& Francis, Abingdon,UK.

Singhal, A., Tewari, V. K., and Prakash, S. (2008). "Utilization of treated spent liquor sludge with fly ash in cement and concrete." Build. Environ., 43(6), 991-998.

Tariq, A., and Yanful, E. K. (2013). "A review of binders used in cemented paste tailings for underground and surface disposal practices." J. Environ. Manage., 131, 138-49.

Taylor, H.F.W., and Gollop, R.S. (1997). "Some chemical and microstructural aspects of concrete Cement-Based Systems, CRC Press, London, UK, 177-184. durability of Portland-limestone cement mortars exposed to magnesium sulfate attack." Cem. Concr Comp., 25, 947-954. limestone cement pastes.” J. Eur. Ceram. Soc., 27(2-3), 1711-1714. between geopolymer and OPC cement concrete." Constr. Build. Mater., 43, 125-130. 
591 Yang, K.-H., Cho, A.-R., Song, J.-K., and Nam, S.-H. (2012). "Hydration products and strength development of calcium hydroxide-based alkali-activated slag mortars." Constr. Build. Mater., $29,410-419$

594 Yang, K.-H., Song, J.-K., Ashour, A. F., and Lee, E.-T. (2008). "Properties of cementless mortars 595 activated by sodium silicate.” Constr. Build. Mater., 22(9), 1981-1989.

596 Yi, Y., Liska, M., and Al-Tabbaa, A. (2013). "Properties and microstructure of GGBS-magnesia pastes." Adv. Cem. Res., 26(2), 114-122.

598 Yüksel, İ., Bilir, T., and Özkan, Ö. (2007). "Durability of concrete incorporating non-ground blast furnace slag and bottom ash as fine aggregate." Build. Environ., 42(7), 2651-2659. 
Table 1. Chemical compositions and physical properties of materials

\begin{tabular}{llll}
\hline & GGBS & DRB20* & CEM I 52.5N \\
\hline Chemical composition & & & \\
$\mathrm{SiO}_{2}$ & 37.0 & 0.037 & 19.47 \\
$\mathrm{Al}_{2} \mathrm{O}_{3}$ & 13.0 & 0.001 & 4.75 \\
$\mathrm{CaO}$ & 40.0 & 33.7 & 63.16 \\
$\mathrm{MgO}$ & 8.0 & 18.9 & 1.43 \\
$\mathrm{~K}_{2} \mathrm{O}$ & 0.6 & 0.011 & 0.62 \\
$\mathrm{Na}_{2} \mathrm{O}$ & 0.3 & 0.016 & 0.28 \\
$\mathrm{SO}_{3}$ & 1.0 & $\mathrm{NM}$ & 2.68 \\
$\mathrm{Fe}_{2} \mathrm{O}_{3}$ & $\mathrm{NM}$ & 0.006 & 3.43 \\
$\mathrm{CO}_{2}$ & $\mathrm{NM}$ & 47.3 & $\mathrm{NM}$ \\
$\mathrm{Cl}$ & $\mathrm{NM}$ & $\mathrm{NM}$ & 0.0094 \\
$\mathrm{LOI}$ & $\mathrm{NM}$ & $\mathrm{NM}$ & 3.26 \\
& & & \\
$\mathrm{Physical} \mathrm{properties}_{\text {Specific surface area }\left(\mathrm{m}^{2} / \mathrm{kg}\right)}$ & & & \\
$\mathrm{Bulk}$ density $\left(\mathrm{kg} / \mathrm{m}^{3}\right)$ & 1050 & 900 & $\mathrm{NM}$ \\
$\mathrm{Average}$ & $\mathrm{NM}$ & 4.9 & \\
\hline
\end{tabular}

*The chemical composition of DRB20 were determined by ICP-OES

NM - Not Measured 
Table 2. Mix design and curing conditions of the samples

\begin{tabular}{llcc}
\hline \multicolumn{1}{c}{ Nomenclature } & \multicolumn{1}{c}{ Composition (by weight) } & w/b & Curing conditions \\
\hline D800S & $10 \%$ D800 + 90\% GGBS & & $24 \mathrm{~h}$ in mould, 28 d in water, and 28, \\
D1000S & $10 \%$ D1000 + 90\% GGBS & 0.35 & $60,90,120 \mathrm{~d}$ in solutions or water \\
PCS & $10 \%$ CEM I + 90\% GGBS & & $24 \mathrm{~h}$ in mould, 28 d in water, and 28 d \\
& & & in solutions or water \\
\hline
\end{tabular}


Table 3. Compressive strengths in water and relative compressive strengths in sulfate solutions

\begin{tabular}{|c|c|c|c|c|c|c|c|c|c|c|}
\hline \multirow{2}{*}{$\begin{array}{l}\text { Age } \\
\text { (d) }\end{array}$} & \multicolumn{3}{|c|}{$\begin{array}{c}\text { Compressive strength of reference } \\
\text { samples cured in water (MPa) }\end{array}$} & \multirow{2}{*}{$\begin{array}{l}\text { Exposure } \\
\text { time (d) }\end{array}$} & \multicolumn{3}{|c|}{$\begin{array}{c}\text { In } 5 \% \mathrm{Na}_{2} \mathrm{SO}_{4} \\
\text { Relative strength (\%) }\end{array}$} & \multicolumn{3}{|c|}{$\begin{array}{c}\text { In } 5 \% \mathrm{MgSO}_{4} \\
\text { Relative strength (\%) }\end{array}$} \\
\hline & D800S & D1000S & PCS & & D800S & D1000S & PCS & D800S & D1000S & PCS \\
\hline initial & 19.3 & 27.8 & 33.4 & & & & & & & \\
\hline 28 & 23.0 & 31.9 & 38.3 & 28 & 106.1 & 96.9 & 104.8 & 92.3 & 87.5 & 82.1 \\
\hline 60 & 23.8 & 36.1 & - & 60 & 106.7 & 93.0 & - & 89.8 & 56.1 & - \\
\hline 90 & 28.9 & 36.2 & - & 90 & 103.9 & 93.9 & - & 59.1 & 43.1 & - \\
\hline 120 & 28.6 & 36.4 & - & 120 & 112.7 & 89.9 & - & 51.0 & 41.3 & - \\
\hline
\end{tabular}




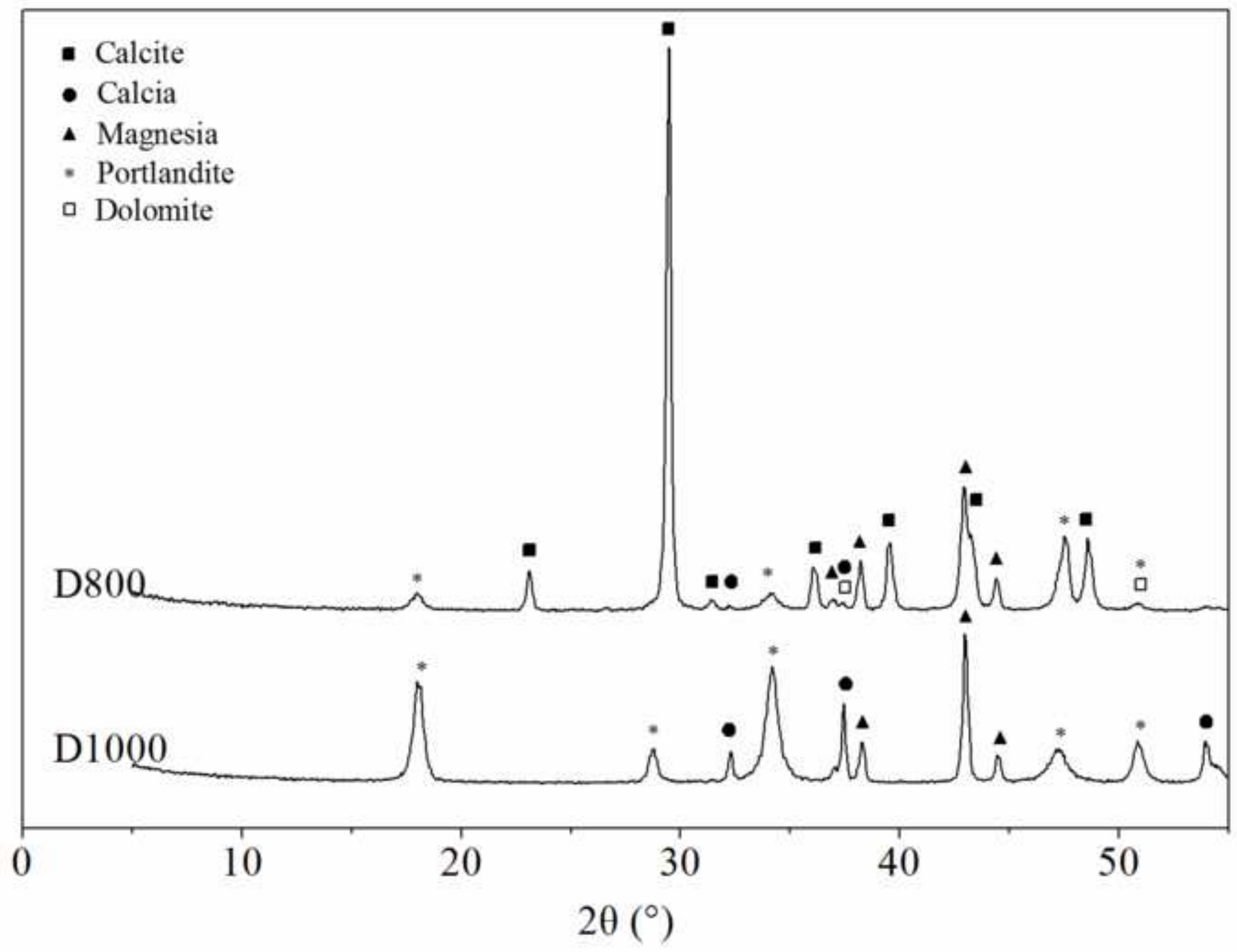




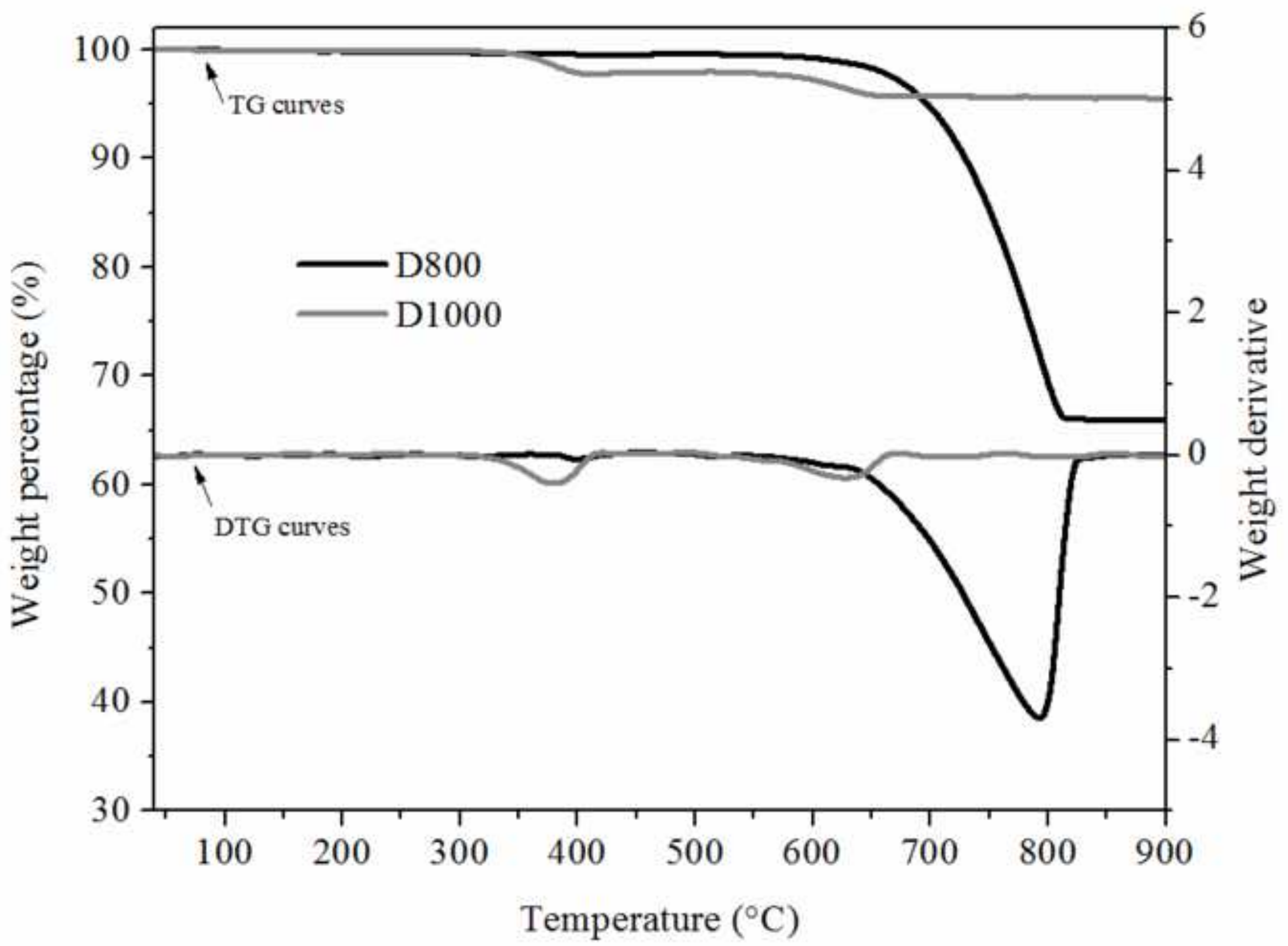




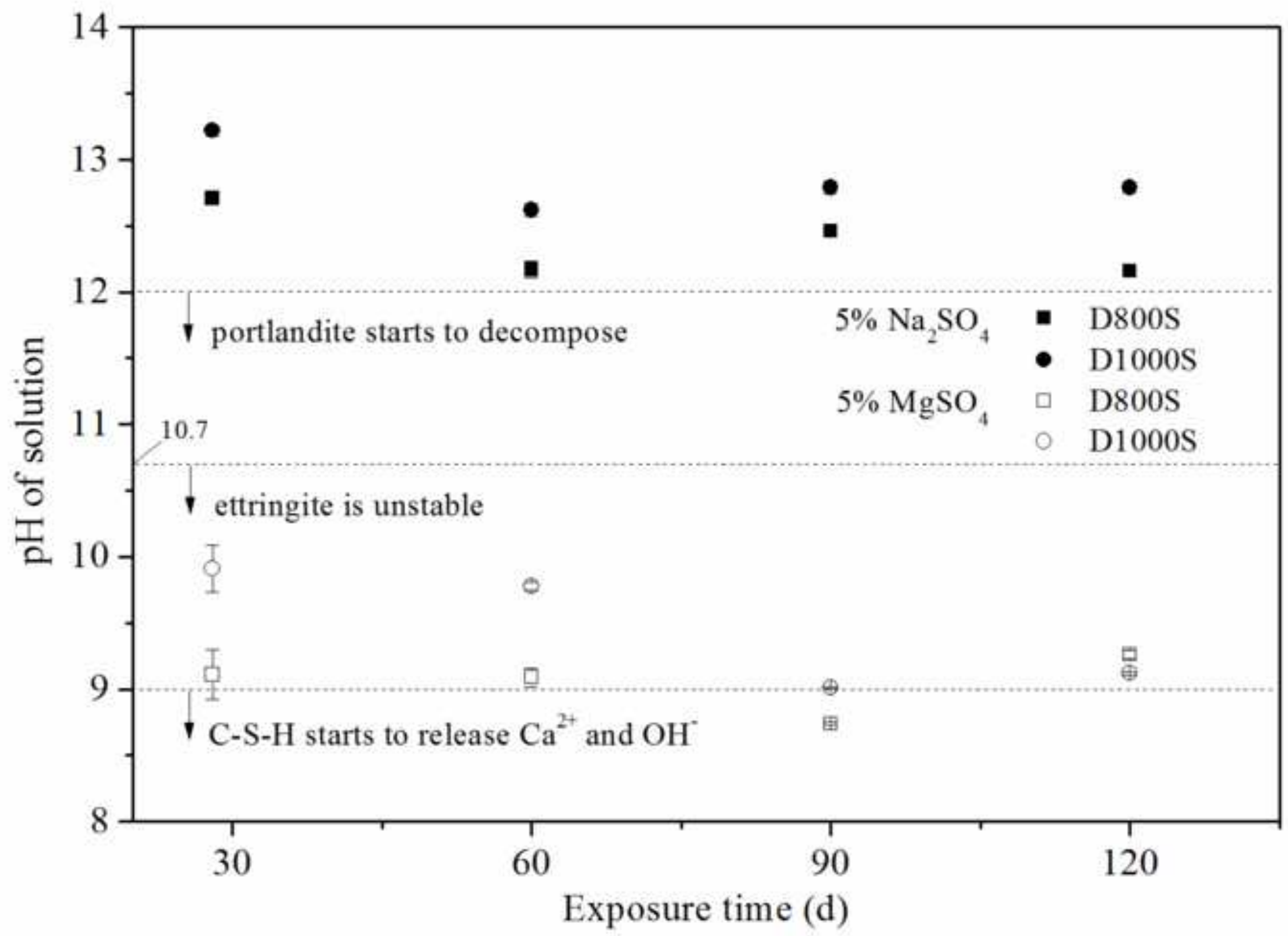




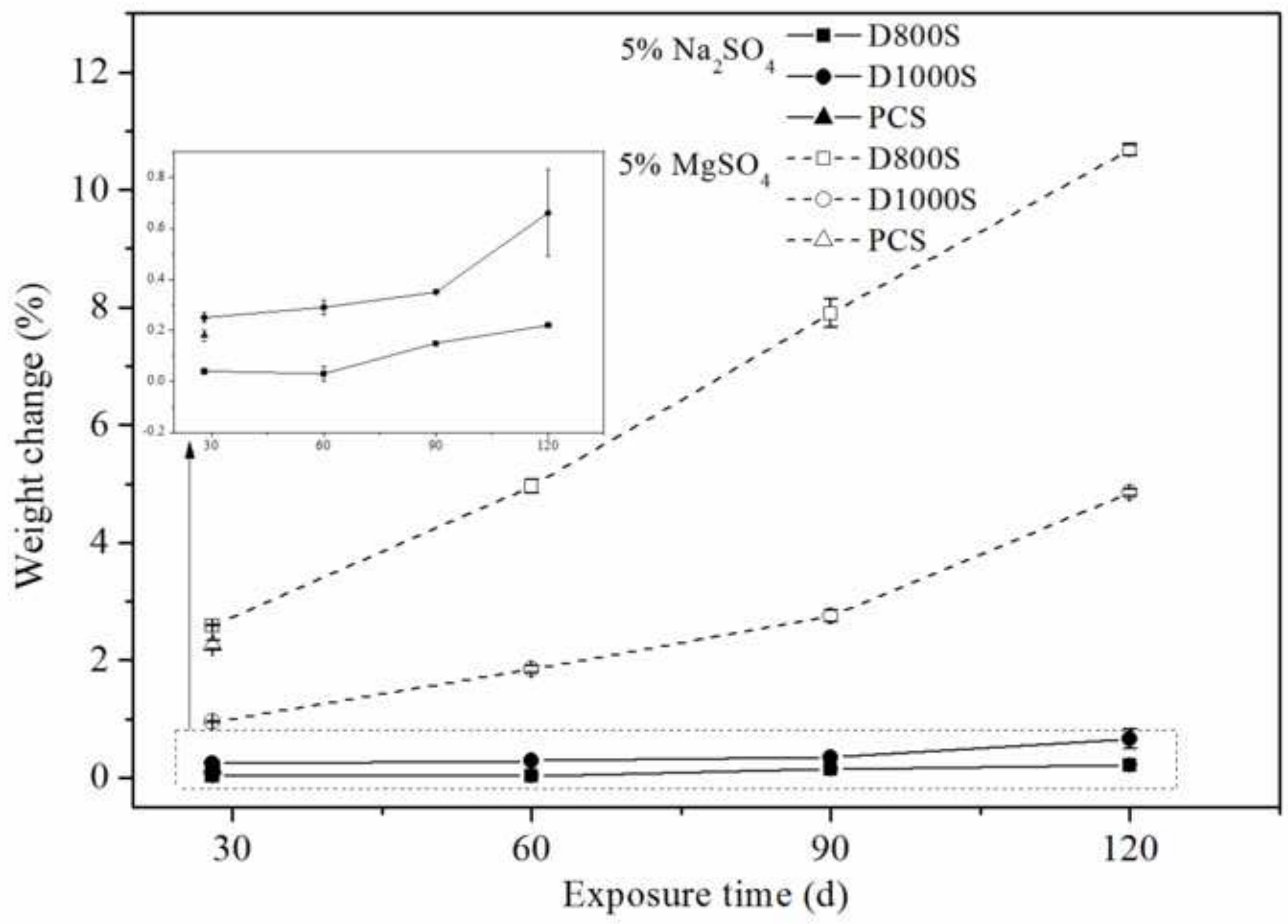




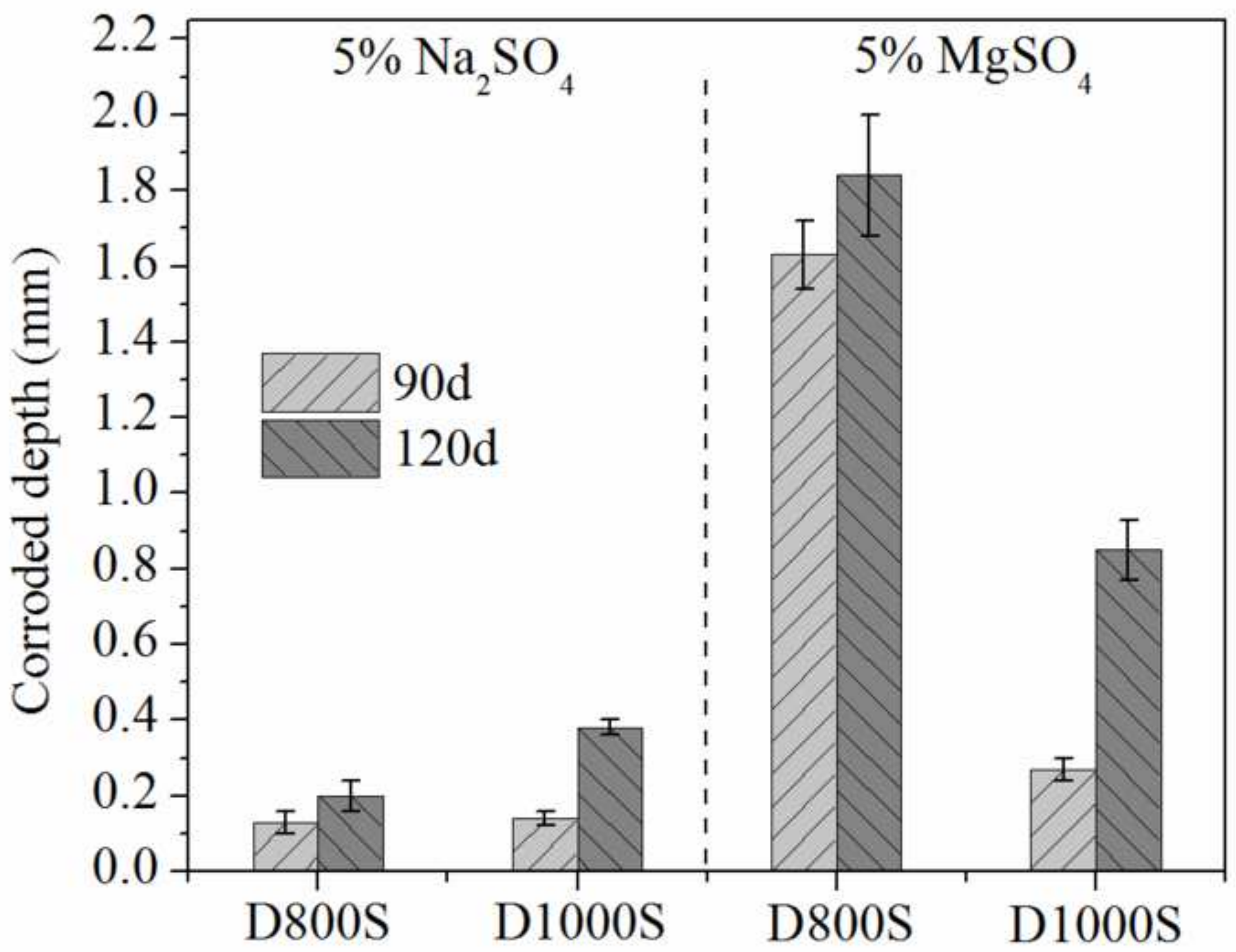


D800S
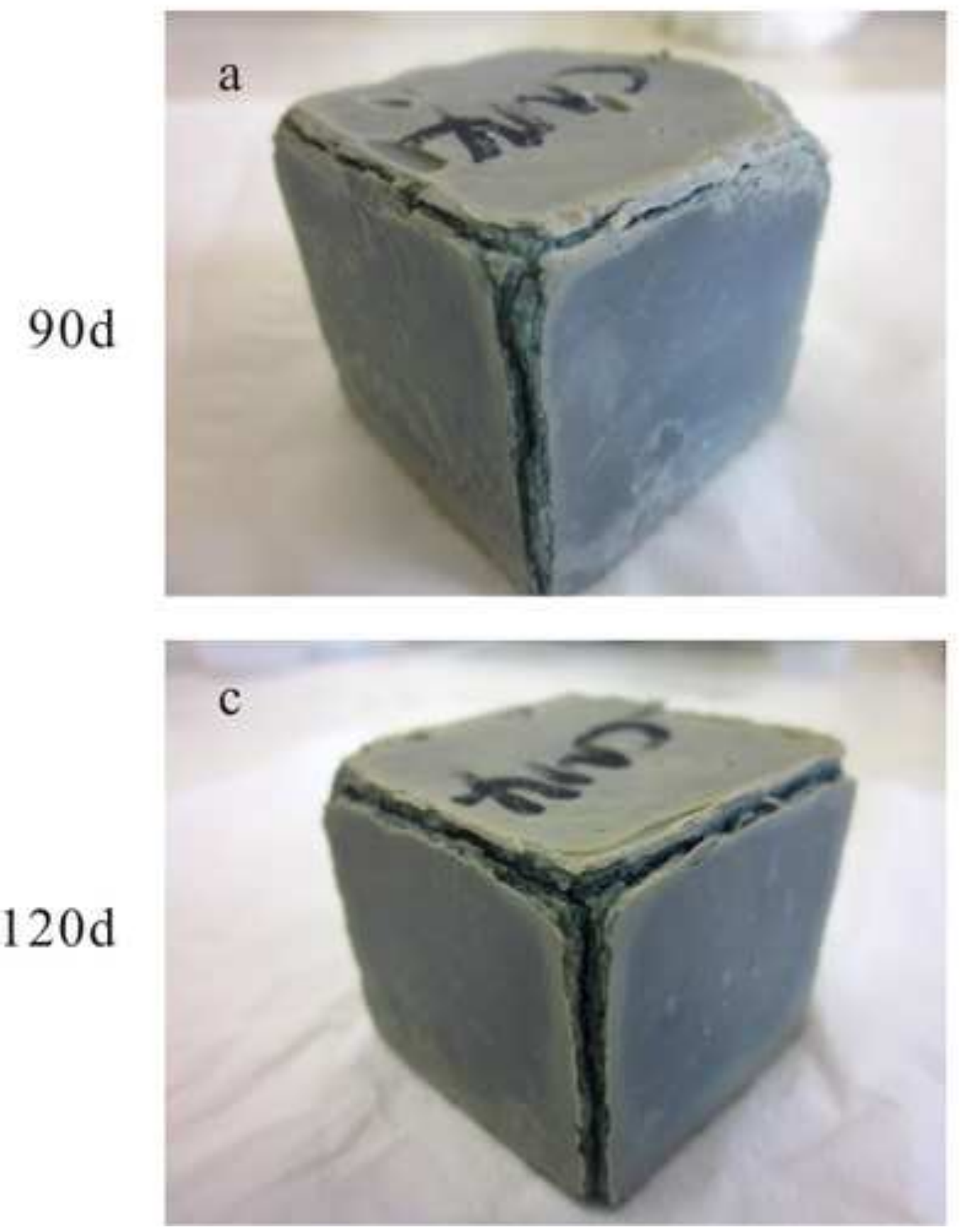

$120 \mathrm{~d}$

\section{D1000S}
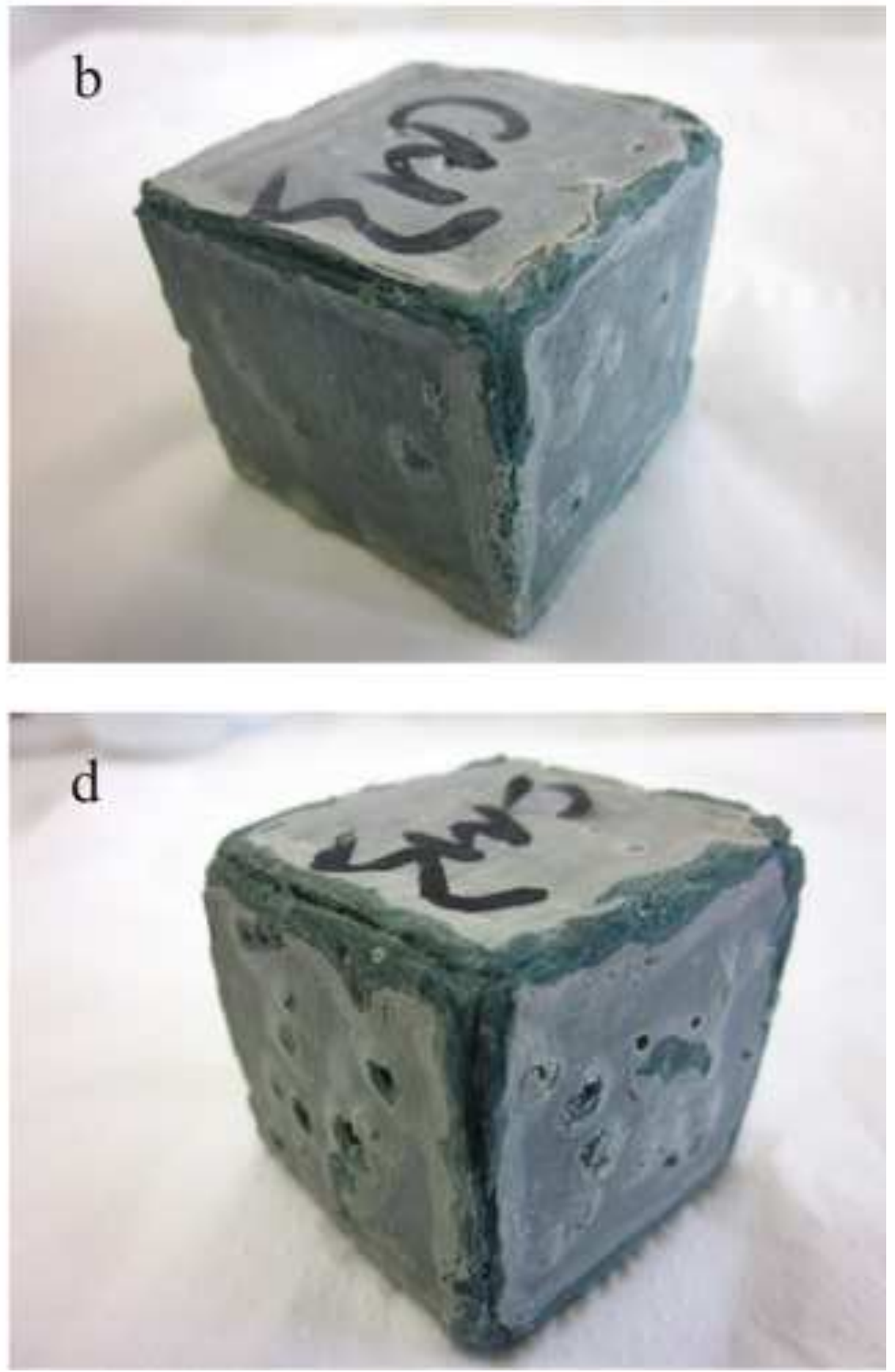

b 


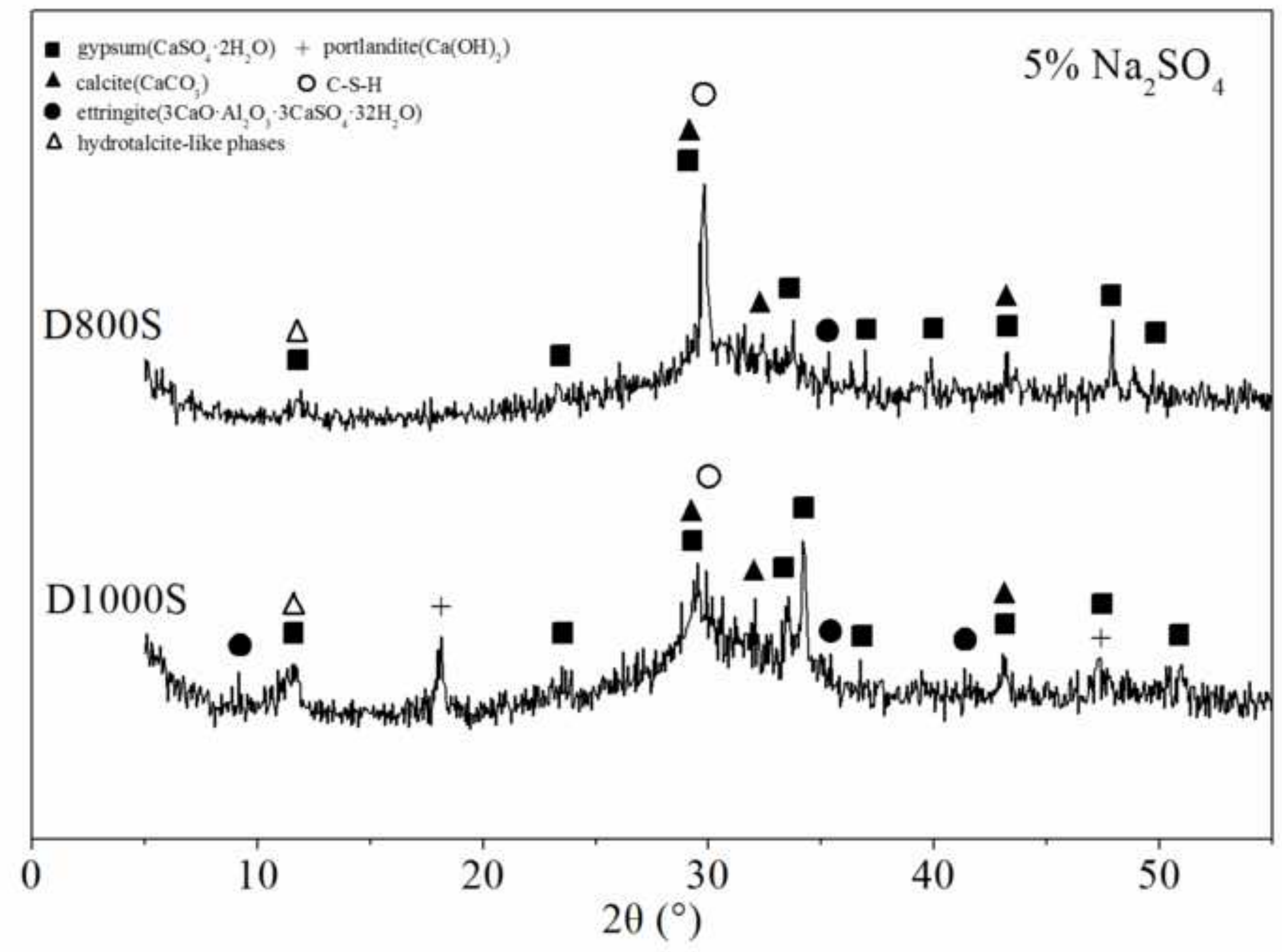




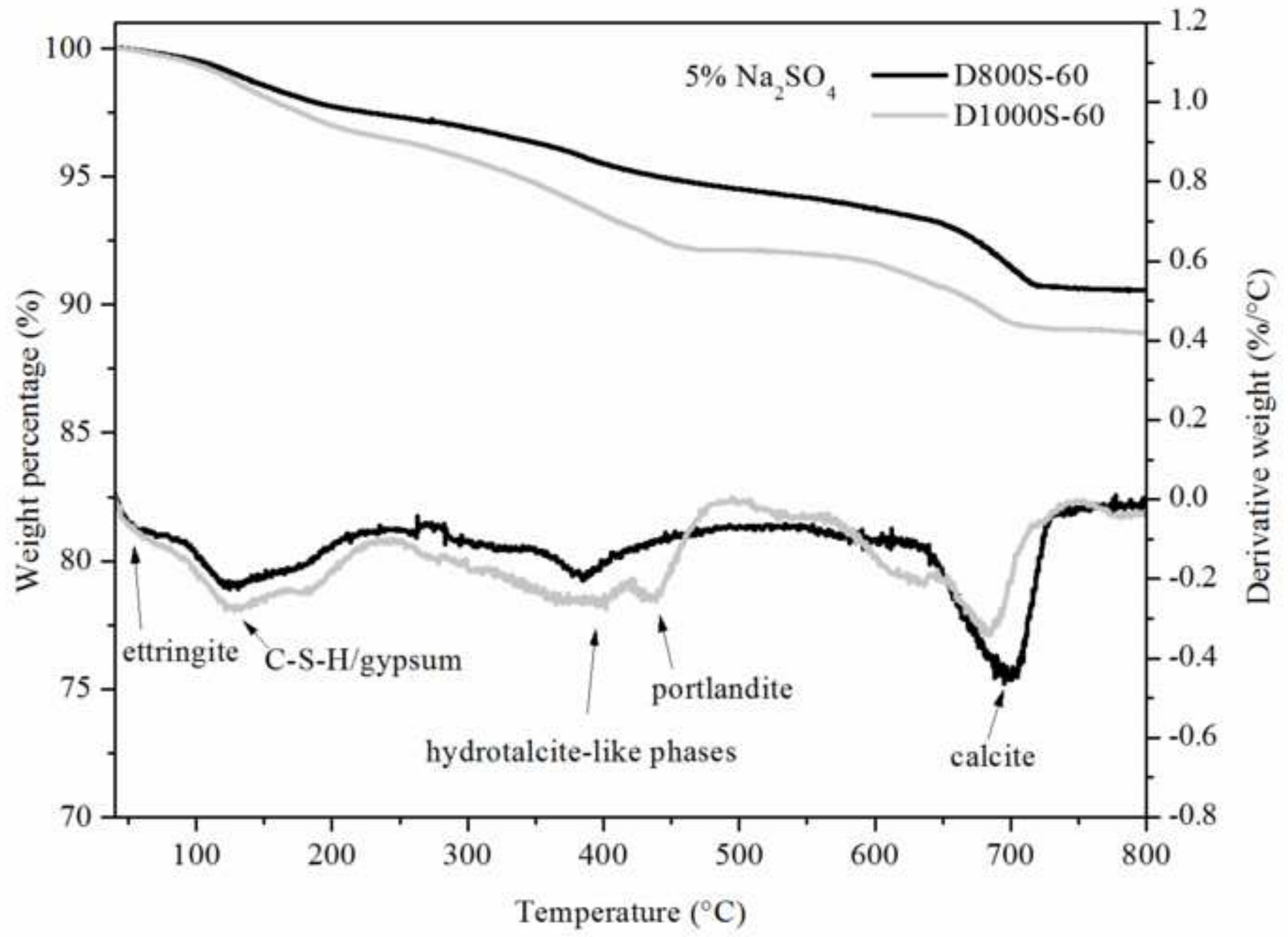




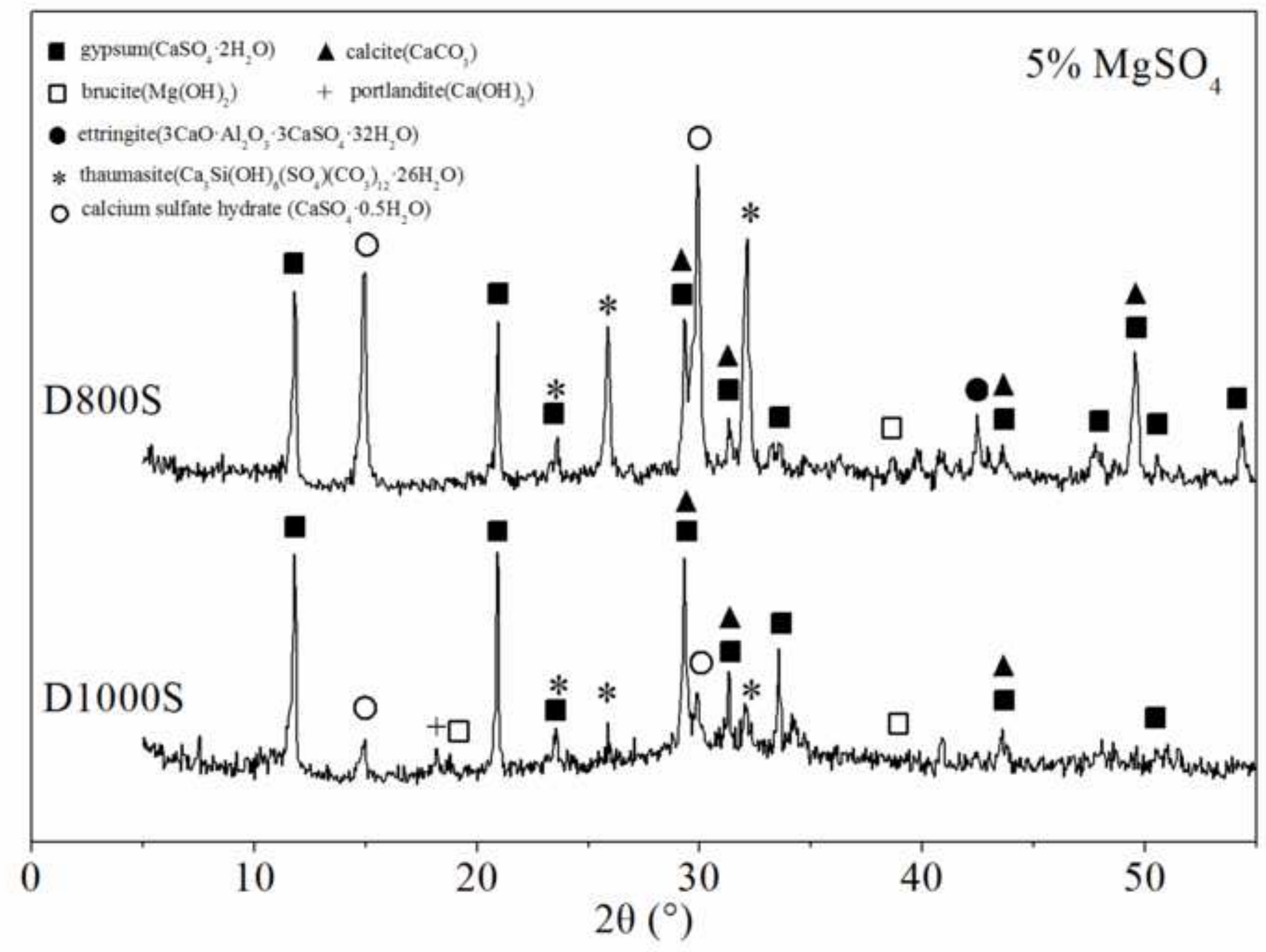




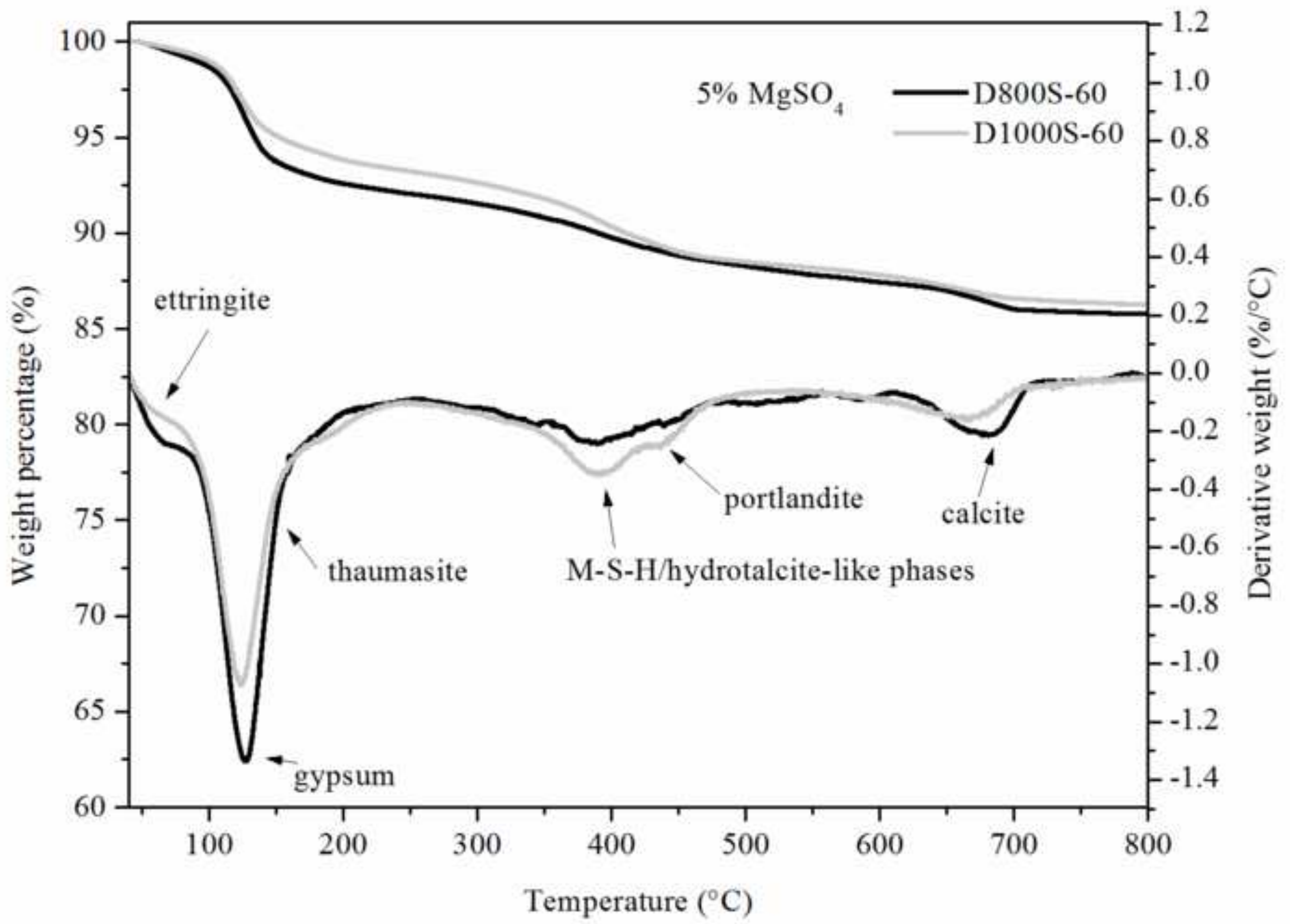



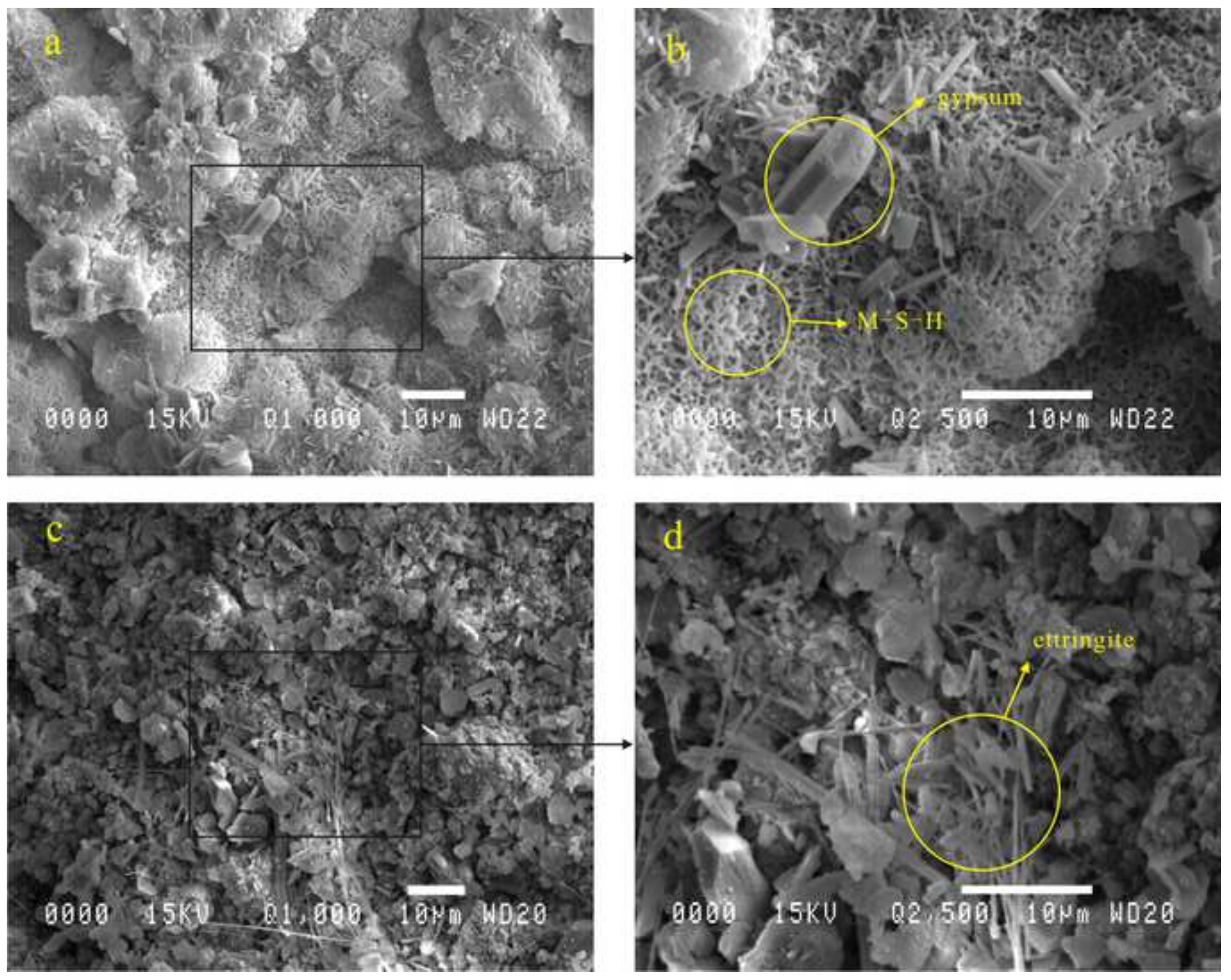

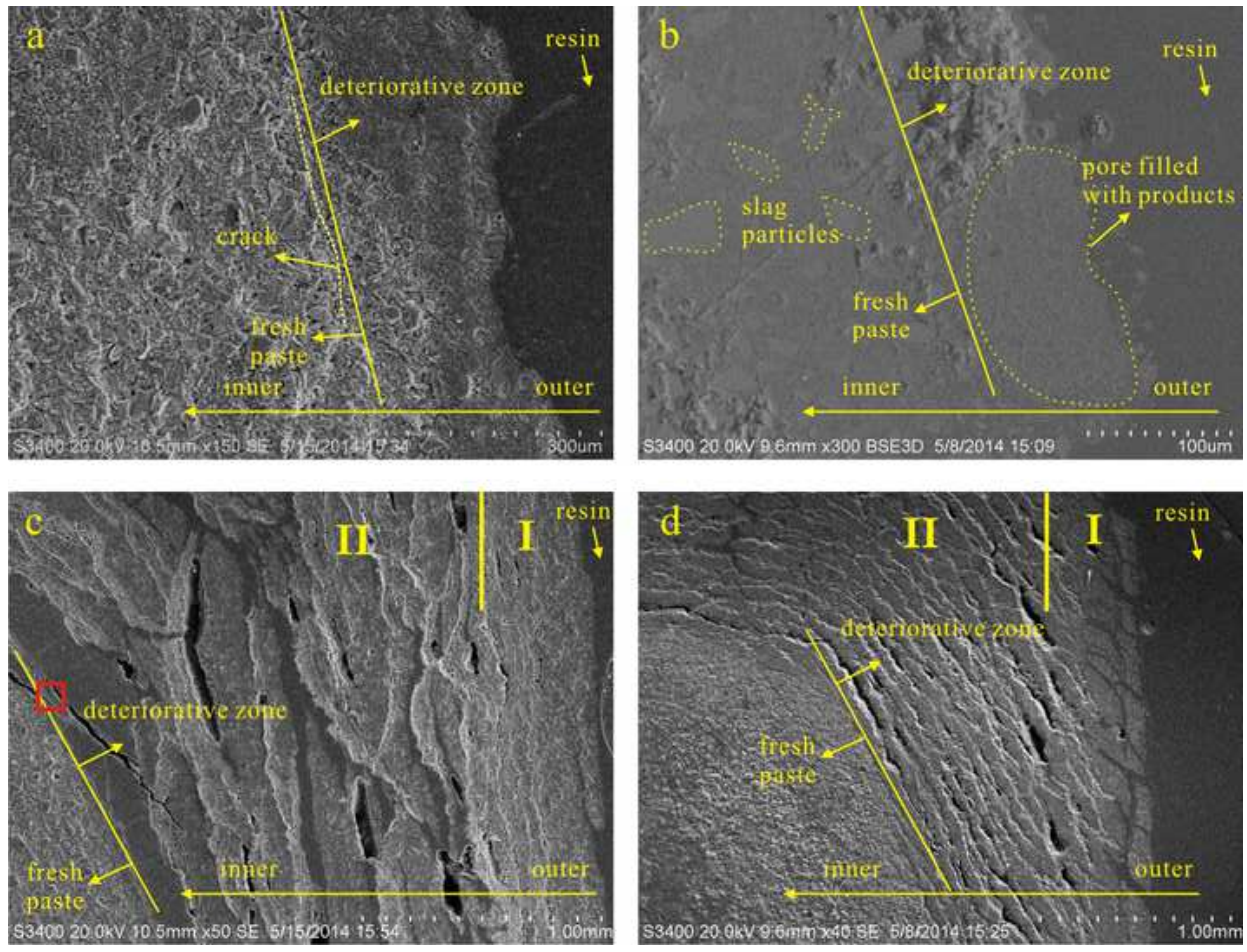
Figure 14

Click here to download Figure: Fig.14.tif
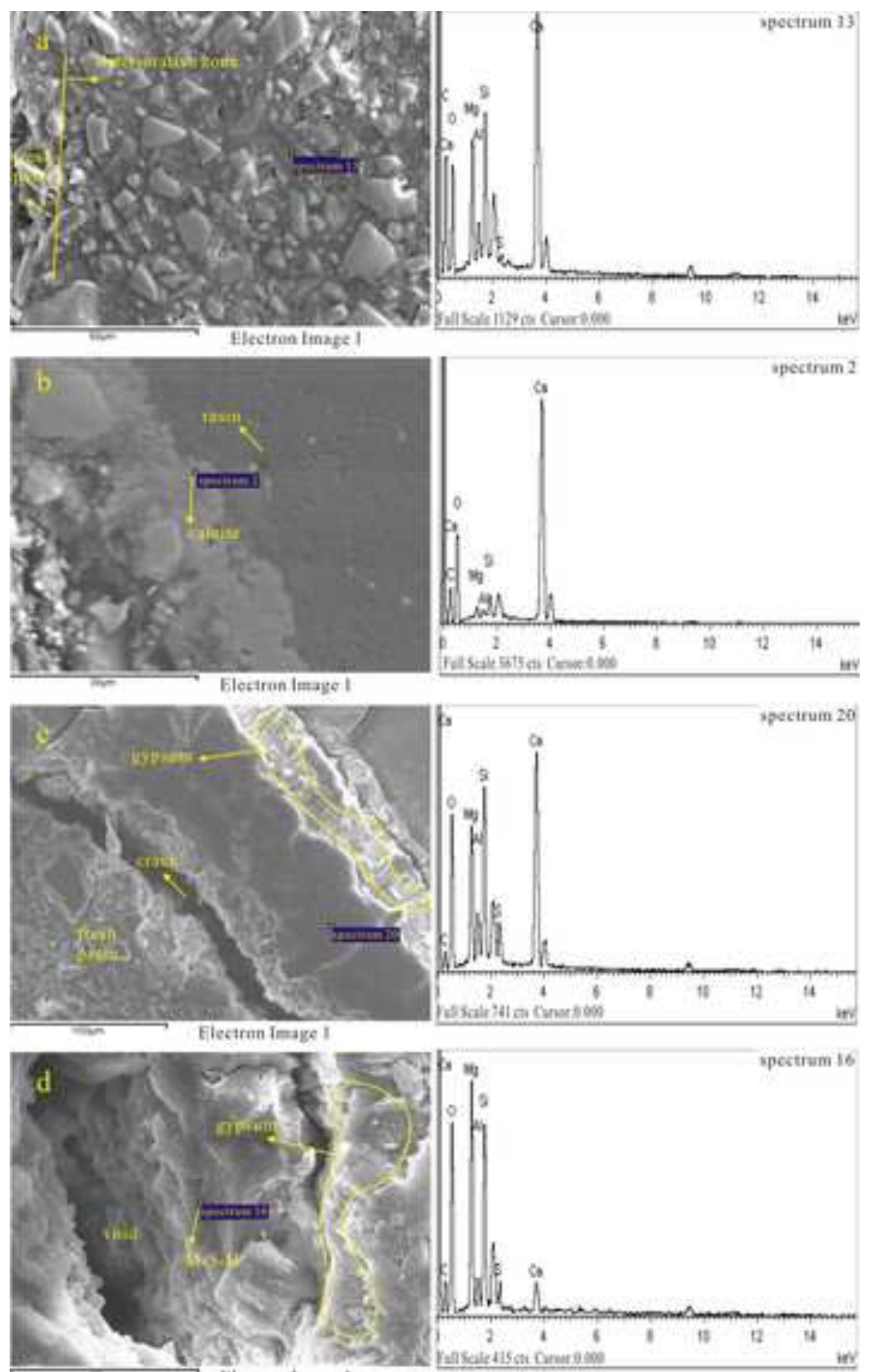

Eilectron inage 1
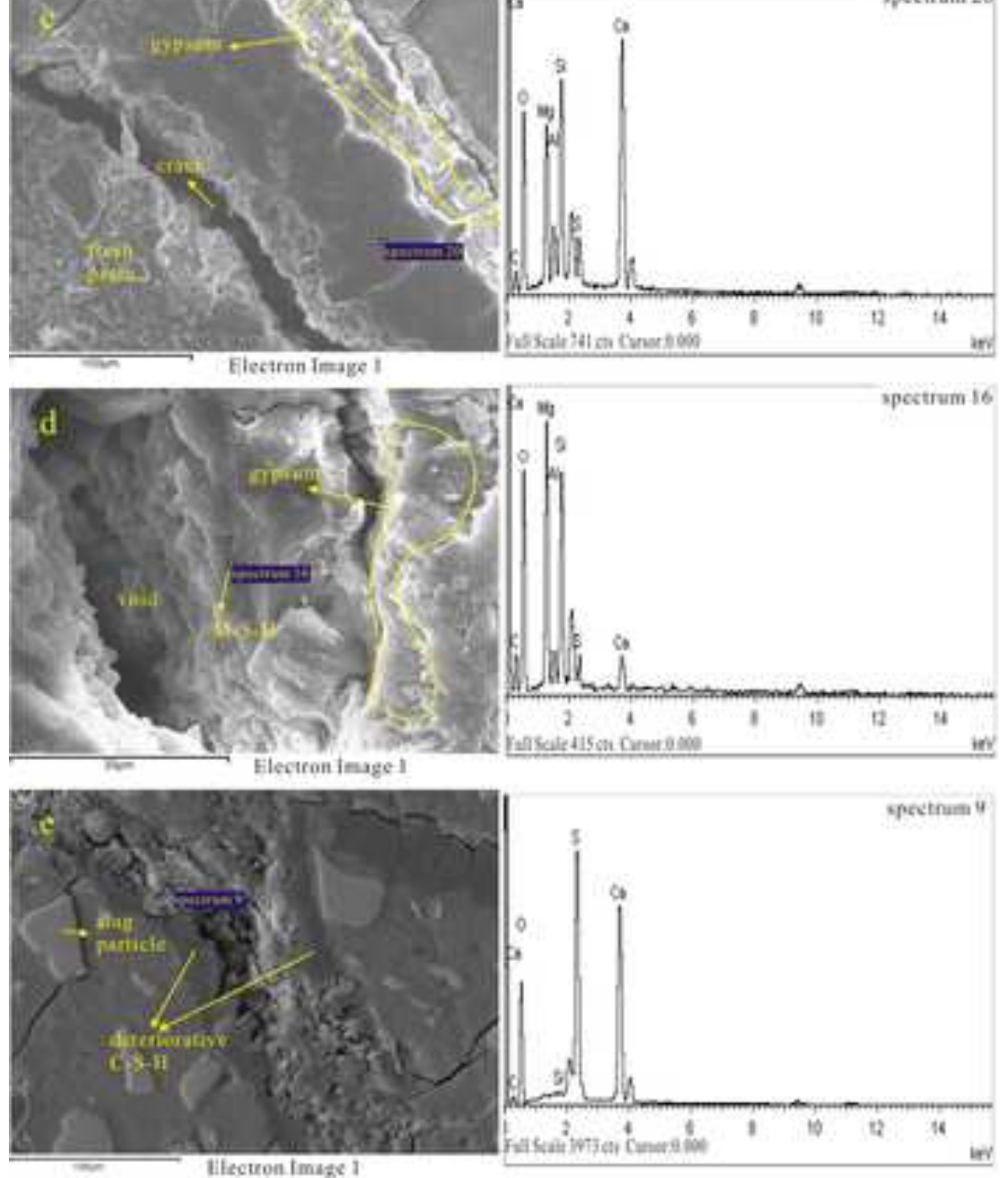

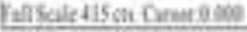




\section{List of figure captions:}

Fig.1 XRD patterns of D800 and D1000

Fig.2 TG/DTG curves of D800 and D1000

Fig. $3 \mathrm{pH}$ of solutions after different exposure times

Fig.4 Weight changes of samples with exposure time

Fig.5 Corroded depths of samples exposed to sulfate solutions

Fig.6 Appearances of samples exposed to $\mathrm{MgSO}_{4}$ solution for 90 and 120 days

Fig.7 XRD diffractograms of degradation products of samples exposed to $\mathrm{Na}_{2} \mathrm{SO}_{4}$ solution for 60 days

Fig. 8 TG/DTG curves of degradation products of samples exposed to $\mathrm{Na}_{2} \mathrm{SO}_{4}$ solution for 60 days

Fig.9 XRD diffractograms of degradation products of samples exposed to $\mathrm{MgSO}_{4}$ solution for 60 days

Fig.10 TG/DTG curves of degradation products of samples exposed to $\mathrm{MgSO}_{4}$ solution for 60 days

Fig.11 Surface of D800S exposed to $\mathrm{Na}_{2} \mathrm{SO}_{4}$ solution for 60 days

Fig.12 Surfaces of samples exposed to $\mathrm{MgSO}_{4}$ solution for 60 days. a, b: D800S; c, d: D1000S

Fig.13 Microstructures of samples exposed to sulfate solutions for 90 days. a, D800S in $\mathrm{Na}_{2} \mathrm{SO}_{4}$ solution; b, D1000S in $\mathrm{Na}_{2} \mathrm{SO}_{4}$ solution; c, D800S in $\mathrm{MgSO}_{4}$ solution; d, D1000S in $\mathrm{MgSO}_{4}$ solution

Fig.14 SEM/EDS results of samples immersed in sulfate solutions for 90 days. a, D800S in $\mathrm{Na}_{2} \mathrm{SO}_{4}$ solution; b, D1000S in $\mathrm{Na}_{2} \mathrm{SO}_{4}$ solution; c and d D800S in $\mathrm{MgSO}_{4}$ solution; e, D1000S in $\mathrm{MgSO}_{4}$ solution 